Portland State University

PDXScholar

Civil and Environmental Engineering

Undergraduate Honors Theses

Summer 2017

\title{
A Statistical Investigation of Lower Columbia River Water Temperature, 1915-2003
}

Corina Christina Mae Overman

Portland State University

Follow this and additional works at: https://pdxscholar.library.pdx.edu/cengin_honorstheses

Part of the Environmental Engineering Commons, and the Water Resource Management Commons Let us know how access to this document benefits you.

\section{Recommended Citation}

Overman, Corina Christina Mae, "A Statistical Investigation of Lower Columbia River Water Temperature, 1915-2003" (2017). Civil and Environmental Engineering Undergraduate Honors Theses. 8.

https://doi.org/10.15760/honors.482

This Thesis is brought to you for free and open access. It has been accepted for inclusion in Civil and Environmental Engineering Undergraduate Honors Theses by an authorized administrator of PDXScholar. Please contact us if we can make this document more accessible: pdxscholar@pdx.edu. 
A STATISTICAL INVESTIGATION OF LOWER COLUMBIA RIVER WATER

TEMPERATURE, 1915-2003

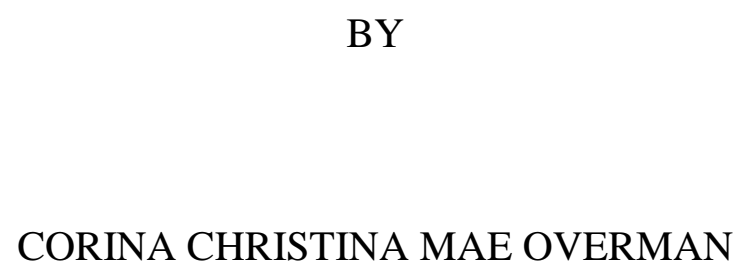

A thesis submitted in partial fulfillment

of the requirement for the degree of

\section{BACHELOR OF SCIENCE} IN

CIVIL AND ENVIRONMENTAL ENGINEERING

Thesis Advisor:

Stefan Talke

Portland State University

(C)2017 


\section{ACKNOWLEDGMENTS}

I would like to acknowledge my advisor, Stefan Talke, for providing guidance, thoughts, and inspiration; David Jay, for the previous work he did on statistical water temperature modeling (see Bottom et al., 2011); and tel jensen, for contributing ideas, criticism, and code debugging. 


\begin{abstract}
The Columbia River is home to anadromous salmon populations that migrate upriver every year to spawn. These fish require cool water temperatures $\left(T_{w}\right)$ to survive. In recent years, high summer $T_{w}$ in the Columbia River has caused increased mortality of salmon. Different possible explanations for increased $T_{w}$ include climate change, deforestation, and decreased summertime streamflow $(Q)$ due to dams. In this study, robust linear regression models of $T_{w}$ based on air temperature $\left(T_{a}\right)$ and $Q$ were developed to examine the change in $T_{w}$ over time. The data was separated into an historical period (1938-1956) and a modern period (1977-2003). Seasonal regression models were used for May through October (summer) and November through April (winter) for each period. Comparison of these models showed that $T_{w}$ has become less sensitive to recent atmospheric heating and cooling. By contrast, analysis suggested that $T_{w}$ has become more sensitive to variations in $Q$. Of the $1.5^{\circ} \mathrm{C}$ increase in maximum summertime $T_{w}$, approximately $1.3^{\circ} \mathrm{C}$ was due to dams and reservoir management based on changes in regression coefficients and average $Q$. A smaller, $0.2^{\circ} \mathrm{C}$ change was estimated to be caused by increasing $T_{a}$ since the mid$20^{\text {th }}$ century. While average maximum $T_{w}$ has increased, both the statistical model and data suggest that the variability in $T_{w}$ from its climatological average has decreased, probably due to reservoir management.
\end{abstract}




\section{TABLE OF CONTENTS}

1.0 INTRODUCTION

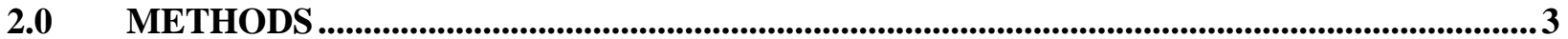

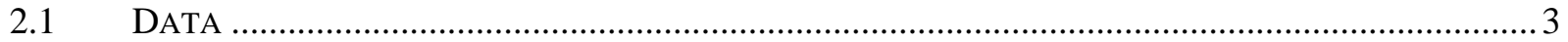

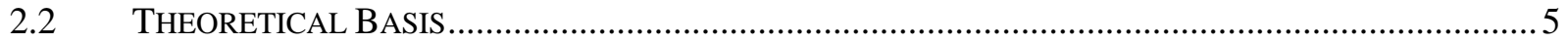

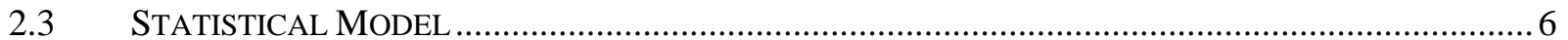

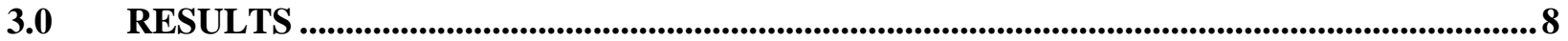

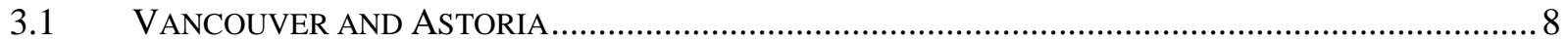

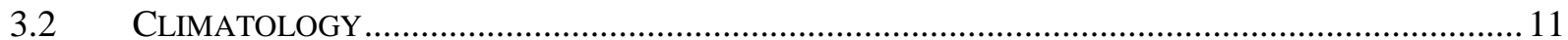

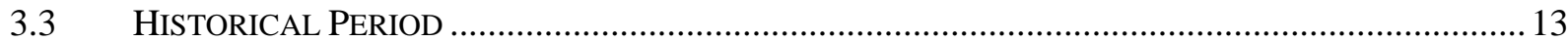

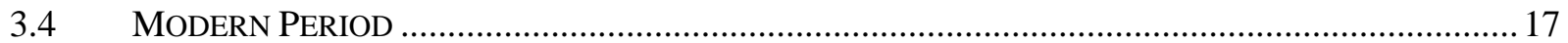

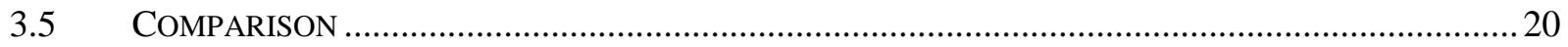

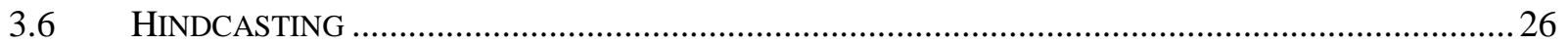

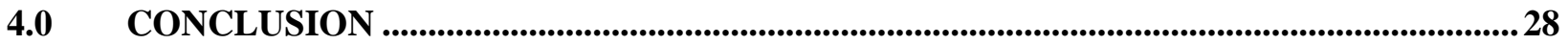

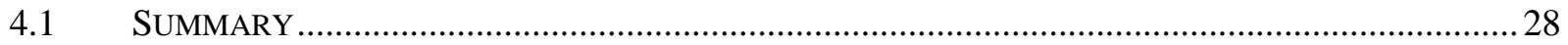

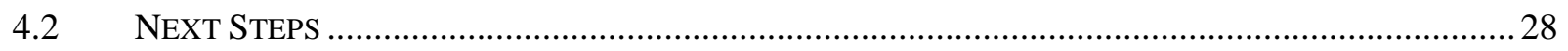

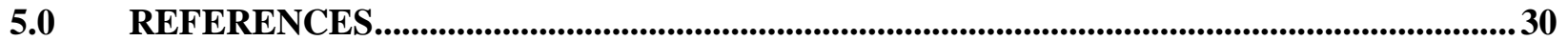




\section{LIST OF TABLES}

Table 1. Regression coefficients for different water temperature models, 1938-1956.............. 15

Table 2. RMSE's for different water temperature models, 1938-1956................................. 16

Table 3. Regression coefficients for different water temperature models, 1977-2003.............. 17

Table 4. Comparison of RMSE's for different water temperature models for 1977-2003. .......... 19

Table 5. Change in regression coefficients for 1938-1956 and 1977-2003 ........................... 22

Table 6. Calculated values for the individual variables in Equation 13, representing August conditions during the time period of annual maximum water temperature $\left(T_{w, \max }\right) \ldots \ldots \ldots \ldots .24$

Table 7. Calculated values of terms in Equation 12 based on values in Table 6 showing contribution from each term to total modeled change in water temperature $\left(T_{w}\right) \ldots \ldots \ldots \ldots \ldots . . . . .24$ 


\section{LIST OF FIGURES}

Figure 1. Map of the Columbia River in Oregon and Washington, adapted from Yearsley (2001).

Figure 2. Monthly average water temperature $\left(T_{w}\right)$ measured at Bonneville Dam and Astoria,

1925-1956. Residuals are Bonneville measurements subtracted from Astoria measurements. 8

Figure 3. Biweekly average water temperature $\left(T_{w}\right)$ measured at Bonneville Dam and Vancouver,

1941-1947. Residuals are Bonneville measurements subtracted from Vancouver

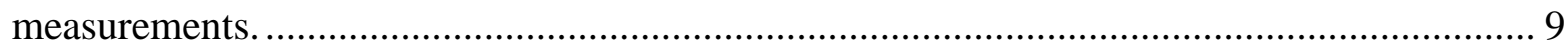

Figure 4. Monthly average water temperature $\left(T_{w}\right)$ measured at Bonneville Dam, Vancouver, and

Astoria with residuals shown by dotted lines, 1941-1947. ............................................. 10

Figure 5. RMSE's between monthly average water temperature $\left(T_{w}\right)$ measured at Bonneville

Dam, Vancouver, and Astoria, 1941-1947................................................................ 10

Figure 6. Climatological means of biweekly average water temperature $\left(T_{w}\right)$ at Bonneville Dam

for 1938-1956 and 1977-2003. Interquartile ranges (IQR's) show values between the first

and third quartile in each data set. $\Delta T_{w}$ is the historical values subtracted from the modern

values

Figure 7. Climatological means of biweekly average air temperature $\left(T_{a}\right)$ for 1938-1956 and

1977-2003. Interquartile ranges (IQR's) show values between the first and third quartile in

each data set. $\Delta T_{a}$ is the historical values subtracted from the modern values.................... 12

Figure 8. Climatological means of biweekly average discharge $(Q)$ at The Dalles for 1938-1956

and 1977-2003. Interquartile ranges (IQR's) show values between the first and third quartile

in each data set. $\Delta Q$ is the historical values subtracted from the modern values.................. 12

Figure 9. Comparison of biweekly average water temperature $\left(T_{w}\right)$ at Bonneville Dam to

climatological average, 1938-1956........................................................................ 13

Figure 10. Comparison of relationships between biweekly average water temperature $\left(T_{w}\right)$ at

Bonneville Dam and flow $(Q)$ at The Dalles at constant basin air temperature $\left(T_{a}\right)$ during

May through October, 1938-1956. Slopes are shown where a significant relationship was

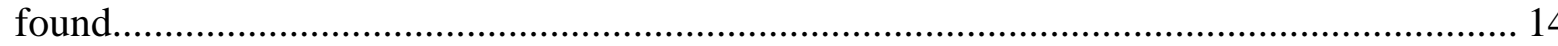

Figure 11. Comparison of relationships between biweekly average water temperature $\left(T_{w}\right)$ at

Bonneville Dam and flow $(Q)$ at The Dalles at constant basin air temperature $\left(T_{a}\right)$ during

November through April, 1938-1956. Slopes are shown where a significant relationship was

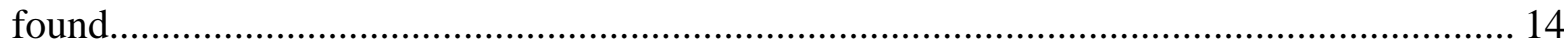

Figure 12. Comparison of relationship between biweekly average water temperature $\left(T_{w}\right)$ at

Bonneville Dam and flow $(Q)$ at The Dalles for May through October (summer) and

November through April (winter), 1938-1956.

Figure 13. Modeled and observed biweekly average water temperature $\left(T_{w}\right)$ at Bonneville Dam,

1938-1956. Residuals show observed measurements subtracted from model results........... 16

Figure 14. Comparison of biweekly average water temperature $\left(T_{w}\right)$ at Bonneville Dam to climatological average, 1977-2003.

Figure 15. Comparison of relationships between biweekly average water temperature $\left(T_{w}\right)$ at

Bonneville Dam and flow $(Q)$ at The Dalles at constant basin air temperature $\left(T_{a}\right)$ during

May through October, 1977-2003. Slopes are shown where a significant relationship was

found...... 
Figure 16. Comparison of relationships between biweekly average water temperature $\left(T_{w}\right)$ at Bonneville Dam and flow $(Q)$ at The Dalles at constant basin air temperature $\left(T_{a}\right)$ during November through April, 1977-2003. Slopes are shown where a significant relationship was found

Figure 17. Comparison of relationship between biweekly average water temperature $\left(T_{w}\right)$ at Bonneville Dam and flow $(Q)$ at The Dalles for May through October (summer) and November through April (winter), 1977-2003.

Figure 18. Modeled and observed biweekly average water temperature $\left(T_{w}\right)$ at Bonneville Dam,

1977-2003. Residuals show observed measurements subtracted from model results. 20

Figure 19. Measured water temperature $\left(T_{w}\right)$ at Bonneville Dam deviation from climatological mean compared to measured basin air temperature $\left(T_{a}\right)$ deviation from climatological mean, $1938-1956$.

Figure 20. Measured water temperature $\left(T_{w}\right)$ at Bonneville Dam deviation from climatological mean compared to measured basin air temperature $\left(T_{a}\right)$ deviation from climatological mean, 1977-2003.

Figure 21. Measured monthly average water temperature $\left(T_{w}\right)$ at Astoria compared to hindcast monthly average $T_{w}$ at Bonneville Dam, 1925-1938. Residuals show modeled Bonneville Dam results subtracted from Astoria measurements. 26

Figure 22. Hindcasted biweekly average water temperature $\left(T_{w}\right)$ at Bonneville Dam, 1915-1938, shown in red and observed biweekly average $T_{w}$ at Bonneville Dam, 1938-1956, shown in blue. 


\subsection{INTRODUCTION}

The Columbia River flows from British Columbia, Canada to the Pacific Ocean, and drains portions of British Columbia, Idaho, Oregon, Washington, and Montana (Figure 1). Major tributaries include the Snake and Willamette Rivers. Since 1933, fourteen hydroelectric dams have been built on the Columbia River. Additionally, there are nineteen dams on the Snake River (Yearsley, 2001) and over one hundred other dams on smaller tributaries in the Columbia River basin (NRC, 1996).

In addition to providing people with electricity and water, the river is home to several different species of salmon. These anadromous fish spend the first one to three years of their lives in the river before migrating to the ocean (Dittman and Quinn, 1996). As they near the ends of their lives, they return to the streams where they were born in order to spawn. Salmon are sensitive to water temperature $\left(T_{w}\right)$, and require different temperature ranges at different life stages. $T_{w}$ above a certain threshold can cause increased disease and mortality as well as decreased growth rates in juveniles. (Boyd and Sturdevant, 1997). The lethal maximum temperature threshold varies between species. Adult steelhead have the lowest, at $21^{\circ} \mathrm{C}$ (Carter, 2006).

Summer $T_{w}$ in the Columbia River has increased during the twentieth century (Quinn and Adams, 1996; Quinn et al., 1997; Bottom el al., 2011; Crozier et al., 2011). In recent years, such as 2015, increased $T_{w}$ has led to decreased salmon counts (NMFS, 2016). Possible explanations for higher $T_{w}$ include climate change, change in streamflow $(Q)$ due to dams (Bottom et al., 2011; Moore, 1967), and changes in riparian shading due to clear cutting and other land-use practices (Johnson, 2004).

Statistical models are often used to determine how changes to weather, climate, and hydrology may influence $T_{w}$ (Moore, 1968; Bottom et al., 2011). Some statistical models of $T_{w}$ use both air temperature ( $\left.T_{a}\right)$ and $Q$ as a basis function (e.g., Webb et al., 2003; Neumann et al., 2003), whereas other statistical models are regressed only against $T_{a}$ (e.g., Stefan and Preud'homme, 1993; Erickson and Stefan, 1996; Pilgrim et al., 1998; Webb and Nobilis, 1997). The appeal of such models is that they are easy to develop and use, are based on readily available data, and can help explain seasonal, interannual, and long-term changes. In the Columbia River basin, Bottom et al. 
(2011) developed a regression for $T_{w}$ based on $T_{a}$ and $Q$ over the 1938-1956 period. Results suggested that dams and reservoir management caused an approximately $0.8^{\circ} \mathrm{C}$ increase in summertime $T_{w}$ and a more than $2^{\circ} \mathrm{C}$ increase in the October and November time period. Similarly, Moore (1968) used regression models to show that the combined effects of dams and heating from the Hanford Nuclear Site accounted for a $1.8^{\circ} \mathrm{C}$ increase in July $T_{w}$ in the Columbia River.

The purpose of this study is to develop a statistical model of $T_{w}$ in the Columbia River that captures the effect of $T_{a}$ and $Q$, both before and after most major main-stem dams were built. The general approach and the data used are similar to Bottom et al. (2011), and the results herein represent both an evolution of that effort and an independent check on those results. Compared to Bottom et al. (2011), this study uses biweekly rather than monthly averaged data, and defines summer/winter regressions as May through October and November through April, rather than January through June and July through December (see 2.0 Methods and 3.0 Results). Additional archival $T_{w}$ data, including Astoria (monthly, 1925-1956) and Vancouver (1941-1947), have been recovered and digitized, and are used to check the representativeness of the $T_{w}$ record at Bonneville Dam (19382003). Moreover, $T_{w}$ data are subsampled to produce both a historical (1938-1956) and modern (1977-2003) statistical model, which enables analysis of possible changes to regression coefficients. Climatological means and anomalies in $T_{w}$ are analyzed and interpreted.

The data analysis and statistical modeling attempt to address the fundamental question: Why are water temperatures in the Columbia River increasing, and to what extent do reservoir management and climate change affect water temperature? While a complex issue, the results presented here are an initial effort to quantify major factors that influence $T_{w}$ over long time scales. 


\subsection{METHODS}

\subsection{Data}

The primary water temperature $\left(T_{w}\right)$ data used in this study came from scroll case measurements taken at Bonneville Dam on the Columbia River, located at the head of tides at river kilometer (rkm) 235, roughly $64 \mathrm{~km}$ upstream of Portland, Oregon (Figure 1). Measurements for the years 1938-1997 (http://www.streamnet.org/files/407/StuTempData.html) consist of one $T_{w}$ value for each day. Additional data for the 1974-2003 period came from the United States Army Corps of Engineers (http://www.nwdwc.usace.army.mil/cgibin/dataquery.pl?k=bon). On days where these data sets overlapped, the arithmetic mean of the measurements from the two data sets was used to obtain a single daily $T_{w}$ measurement. The latter data set primarily contains daily measurements, but for some days there are multiple measurements. In these instances, the arithmetic mean of all the measurements for the day was used as a daily average. For some days, there is no recorded $T_{w}$.

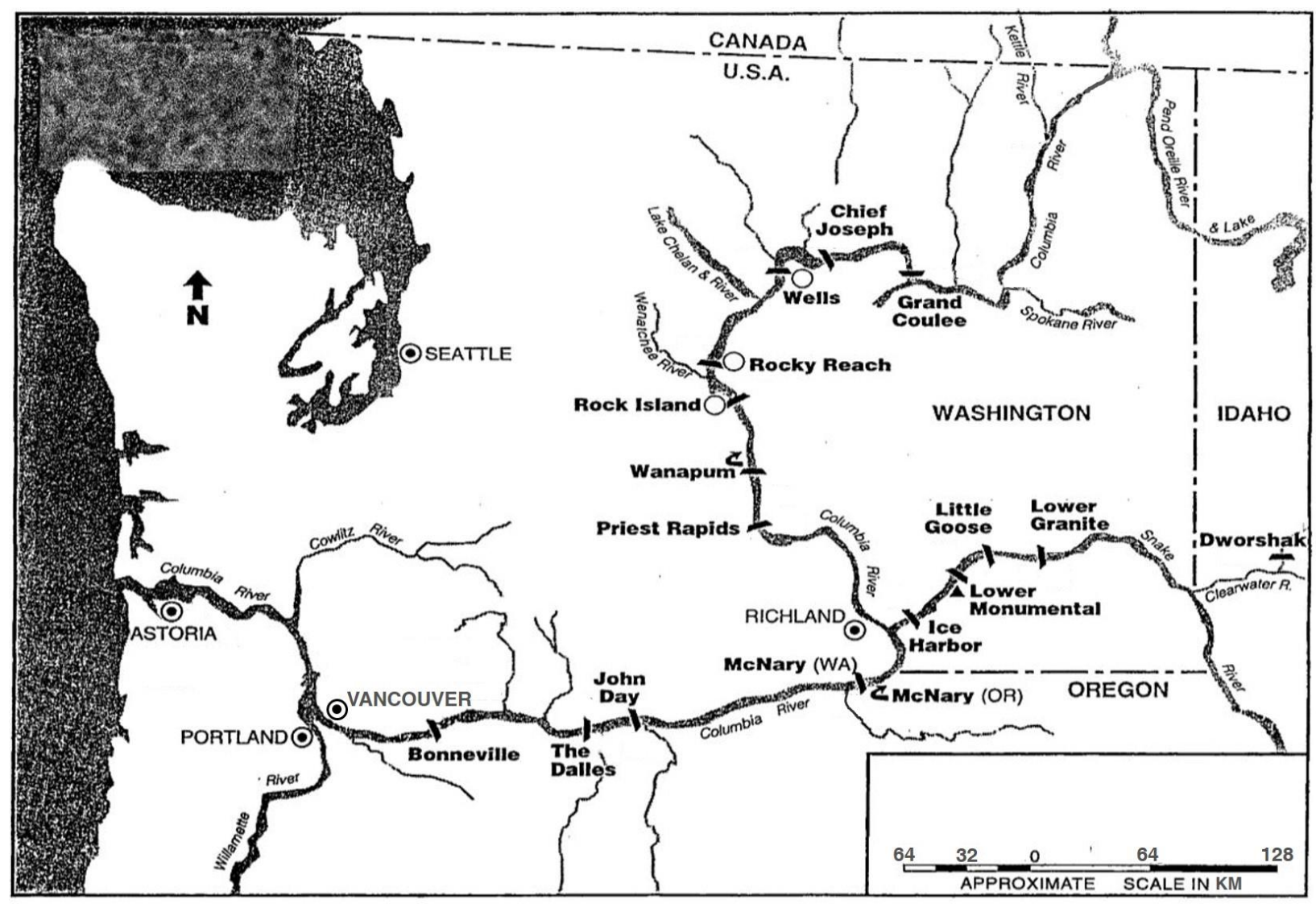

Figure 1. Map of the Columbia River in Oregon and Washington, adapted from Yearsley (2001). 
In the entire sixty-five-year data set, there are 361 days with no $T_{w}$ measurement. More recent data from Bonneville Dam will be analyzed in a follow-on study.

Daily mean discharge $(Q)$ for the Columbia River was measured at The Dalles, approximately 70 $\mathrm{km}$ upriver from Bonneville Dam. The United States Geological Survey has continuous daily measurements dating back 1878 (https://waterdata.usgs.gov/usa/nwis/uv?14105700 [May 2017]).

Following Bottom et al. (2011), biweekly average air temperature $\left(T_{a}\right)$ data (1915-2003) for the Columbia River Basin was obtained for multiple sub-basins from the Surface Water Modeling group at the University of Washington (available from http://www.hydro.washington.edu/ Lettenmaier/Data/gridded/) (Hamlet and Lettenmaier, 2005). To obtain an average $T_{a}$ for the entire basin, measurements from each sub-basin were weighted by the relative area of the sub-basin to the entire basin.

Daily $T_{w}$ and $Q$ measurements were averaged over two-week periods to match the biweekly $T_{a}$ data. The reference date for each two-week period is the average day of the period.

While the combination of the $T_{w}, Q$, and $T_{a}$ data sets spans almost the entire period from 19382003, the years 1957-1976 were not considered in this analysis. This is because the river experienced excess heating from the Hanford Nuclear Site during those years (Bottom et al., 2011). Since part of this work aims to find trends in $T_{w}$, including these years would not accurately represent present conditions or historical conditions. The remaining years were separated into historical and modern periods. The historical period (1938-1956) represents the years when the river was less affected by dams and reservoir management. The modern period (1977-2003) represents the years when most of the existing dams had been constructed.

Monthly average $T_{w}$ and density measurements from Astoria, Oregon (rkm 29) for 1925-1956 were obtained from United States Coast and Geodetic Survey records (USCGS, 1954; USCGS, 1954; USCGS, 1962). These were used to verify the results of estimated Bonneville $T_{w}$ for 1925-1938, which were obtained using the statistical model described below.

Additional daily $T_{w}$ measurements of the Columbia River from Vancouver, Washington (rkm 171), were available for 1941-1947 from the National Centers for Environmental Information (https:// 
www.ncdc.noaa.gov/EdadsV2/). These were digitized and compared with the other $T_{w}$ measurements to assess accuracy and variance.

\subsection{Theoretical Basis}

The one-dimensional heat transfer in a river can be described by the following partial differential equation:

$$
\frac{\partial T_{w}}{\partial t}=-\frac{1}{A} \frac{\partial Q T_{w}}{\partial x}+\frac{\partial}{\partial x}\left(K \frac{\partial T_{w}}{\partial x}\right)+\frac{\Sigma H}{\rho c_{p} d}
$$

where $T_{w}$ is a function of both along-channel distance $(x)$ and time $(t), A$ is the river cross-section, $K$ is the dispersion coefficient, $H$ is the net heat flux between the river and the atmosphere, $\rho$ and $c_{p}$ are the density and specific heat of water, and $d$ is the river depth (Gu, 1998; Wagner et al., 2011). The first term on the right side of the equation, representing advection, as well as the second term, representing dispersion, are often small compared to the third term, representing atmospheric heat flux (Gu, 1998; Wagner et al., 2011). Neglecting these terms, Equation 1 can then be written

$$
\frac{\partial T_{w}}{\partial t}=\frac{\Sigma H}{\rho c_{p} d}
$$

Net heat flux comprises radiative flux, evaporative flux, and convective flux. The largest contributor to $T_{w}$ change is radiative flux from incoming solar radiation (Wagner et al., 2011). $T_{a}$ effects evaporative and convective fluxes in water, which are small, but $T_{a}$ is also dependent on solar radiation (Moore, 1967). So, while $T_{a}$ does not directly affect $T_{w}$, the two are positively correlated based on their mutual dependence on solar radiation (Johnson, 2004).

The rate at which a body of water heats and cools is inversely related to its volume. In a river, volume (and river depth) increases with $Q$, so increased $Q$ will have a negative effect on $T_{w}$ (Webb

et al., 2003). Additionally, an increase in $Q$ corresponds to an increase in stream velocity. This causes a parcel of water to have a shorter residence time and therefore less time to absorb heat (Mayer, 2012).

Based on these theoretical considerations, a statistical model can be developed to predict $T_{w}$ based on $T_{a}$ and $Q$. While the $T_{w} / T_{a}$ correlation is not linear when $T_{a}$ is below freezing or above $25^{\circ} \mathrm{C}$ 
(Erickson and Stefan, 2000; Mohseni and Stefan, 1999; Morrill et al., 2005), linear regression models based on $T_{a}$ do well at weekly or monthly time scales (Benyahya et al., 2007; Erickson and Stefan, 2000; Pilgrim et al., 1998; Webb et al., 2003). Such a model has the form

$$
T_{w}(t)=\beta_{0}+\beta_{1} T_{a}(t)+\beta_{2} Q(t)
$$

where $\beta_{0}, \beta_{1}$, and $\beta_{2}$ are regression coefficients. Equation (3) can be modified by introducing a time lag to the $T_{a}$ term, such that

$$
T_{w}(t)=\beta_{0}+\beta_{1} T_{a}(t-1)+\beta_{2} Q(t)
$$

where $T_{w}$ at a given time is based on $T_{a}$ from the previous time step. Stefan and Preud'homme (1993) showed that a time lag on $T_{a}$ improves such models and that the ideal time lag increases with river size.

\subsection{Statistical Model}

Various linear regression models of $T_{w}$ at Bonneville Dam based on Columbia Basin $T_{a}$ and $Q$ at The Dalles were tested for the historical and modern periods, separately. Variations included regressions based on January through December data, or regressions separated into two six-month

subsets. Different time lag combinations of two or four weeks for $T_{a}$ were tested for all models, as well as different sets of six-month periods. Model coefficients were calculated using robust regression with a weighting function given by Equation 5 (Ul-Saufie et al., 2012).

$$
w=\frac{1}{\left(1+r^{2}\right)}
$$

Robust regression is less affected by outliers than ordinary least squares regression, so errors in the data do not influence the coefficient estimates as much. All coefficients considered for the final models were significant at a 95\% confidence level.

Models were compared using their root mean squared errors (RMSE). This provides a measure of how well the model approximates measured data and is computed as 


$$
R M S E=\sqrt{\sum \frac{\left(\hat{y}_{t}-y_{t}\right)^{2}}{n}}
$$

where $\hat{y}_{t}$ is the predicted value, $y_{t}$ is the measured value and $n$ is the sample size. A lower RMSE represents a better model. RMSE's were calculated for the entire model as well as for annual maximum $T_{w}$. This tested how well a model approximated the measured annual maximum $T_{w}$.

Test statistics for checking whether two means or regression slopes were significantly different at a $95 \%$ confidence level were computed as

$$
t=\frac{\bar{x}-\bar{y}}{\sqrt{\frac{s_{x}^{2}}{n}+\frac{s_{y}^{2}}{m}}}
$$

where $\bar{x}$ and $\bar{y}$ are the means of each sample, $s_{x}^{2}$ and $s_{y}^{2}$ are the standard deviations of each sample, and $n$ and $m$ are the corresponding sample sizes. The degrees of freedom for the $\mathrm{t}$-distribution were calculated using the Welch-Satterthwaite equation as follows:

$$
d f=\frac{\left(\frac{s_{x}^{2}}{n}+\frac{s_{y}^{2}}{m}\right)^{2}}{\frac{\left(\frac{s_{x}^{2}}{n}\right)^{2}}{n-1}+\frac{\left(\frac{s_{y}^{2}}{m}\right)^{2}}{m-1}}
$$




\subsection{RESULTS}

\subsection{Vancouver and Astoria}

Water temperature $\left(T_{w}\right)$ measurements taken at Bonneville Dam could be affected by natural spatial variability (e.g., top-to-bottom stratification), by daily heating and cooling cycles (if measurement times were inconsistent), or by measurement error. Before developing a regression model, the representativeness and accuracy of $T_{w}$ measurements from Bonneville Dam were therefore checked against Astoria and Vancouver $T_{w}$ records (Figures 2 and 3).

Results show that monthly-averaged $T_{w}$ measurements at Bonneville Dam were sometimes slightly higher in the summer than Astoria, but much lower than Astoria in winter, with an overall RMSE of $1.26^{\circ} \mathrm{C}$ (Figure 2). Monthly average density measurements for Astoria for those years indicated that salinity was generally below 2 parts per thousand, indicating that the $T_{w}$ measurements predominately represent river rather than ocean temperatures. For the months of May through October the RMSE was $1.02^{\circ} \mathrm{C}$ and for the months of November through April it was $1.46^{\circ} \mathrm{C}$.

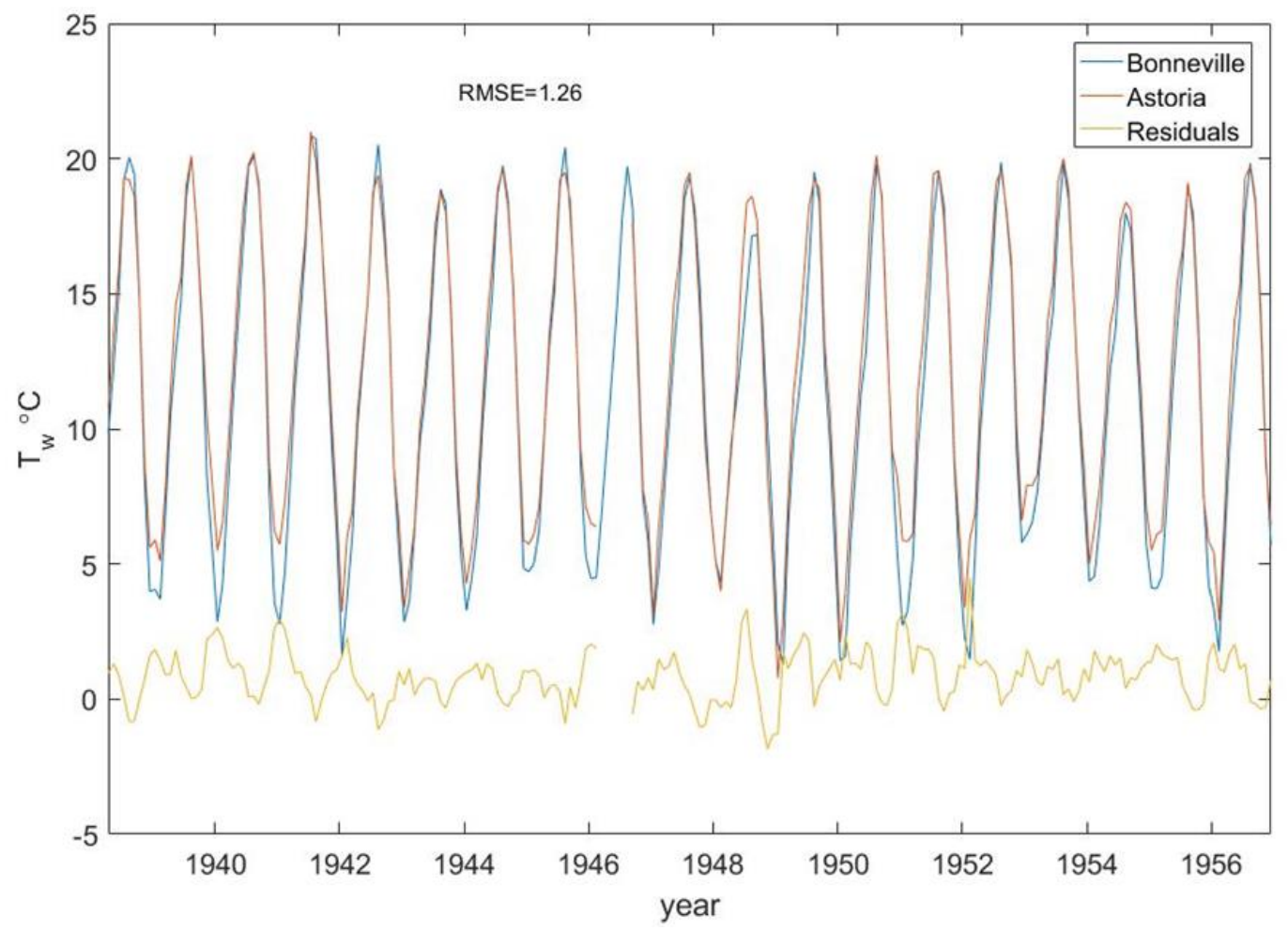

Figure 2. Monthly average water temperature $\left(T_{w}\right)$ measured at Bonneville Dam and Astoria, 1925-1956. Residuals are Bonneville measurements subtracted from Astoria measurements. 
The large differences in wintertime $T_{w}$ may reflect the effect of warmer, wintertime river flow from coastal tributaries such as the Willamette River, which drain a more temperate region than the colder interior and may not be reflected in Bonneville (or Vancouver) measurements. Some heating of the lower Columbia River between Bonneville and Astoria may also occur in the winter. Though salinity intrusion during low flow conditions may also contribute to the warmer $T_{w}$ at Astoria, the monthly averaged density measurements suggest this bias is small or negligible.

The representativeness and accuracy of $T_{w}$ measurements from Bonneville Dam were also tested by comparing the daily measurements with Vancouver measurements for the years 1941-1947. This resulted in an RMSE of $0.67^{\circ} \mathrm{C}$ (Figure 3), indicating that the two data sets agree well.

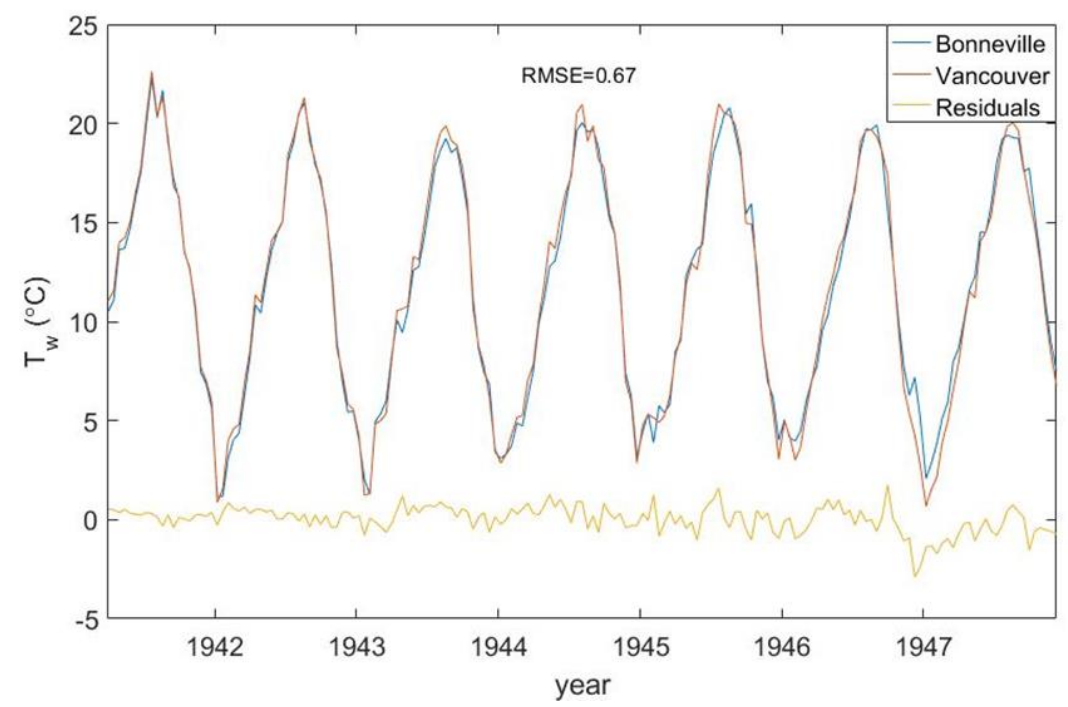

Figure 3. Biweekly average water temperature $\left(T_{w}\right)$ measured at Bonneville Dam and Vancouver, 1941-1947. Residuals are Bonneville measurements subtracted from Vancouver measurements.

Monthly average $T_{w}$ measurements for Bonneville Dam, Vancouver, and Astoria were compared for the years 1941-1947. Vancouver and Bonneville Dam $T_{w}$ measurements generally matched well and were much closer to one another than to Astoria (Figure 4). The residuals and RMSE's between these three locations did not change much from 1941-1945, but in 1946 and 1947 there was a sharp increase in discrepancy between Astoria and Vancouver. Residuals and RMSE's between Bonneville Dam and Vancouver also increased in those years, but to a lesser extent (Figure 5). The increase in discrepancies between the three $T_{w}$ data sets over time indicates that data quality likely decreased. The change in RMSE is more noticeable between Vancouver and 
Bonneville and Vancouver and Astoria than between Bonneville and Astoria, suggesting that the problem lies with the Vancouver data.

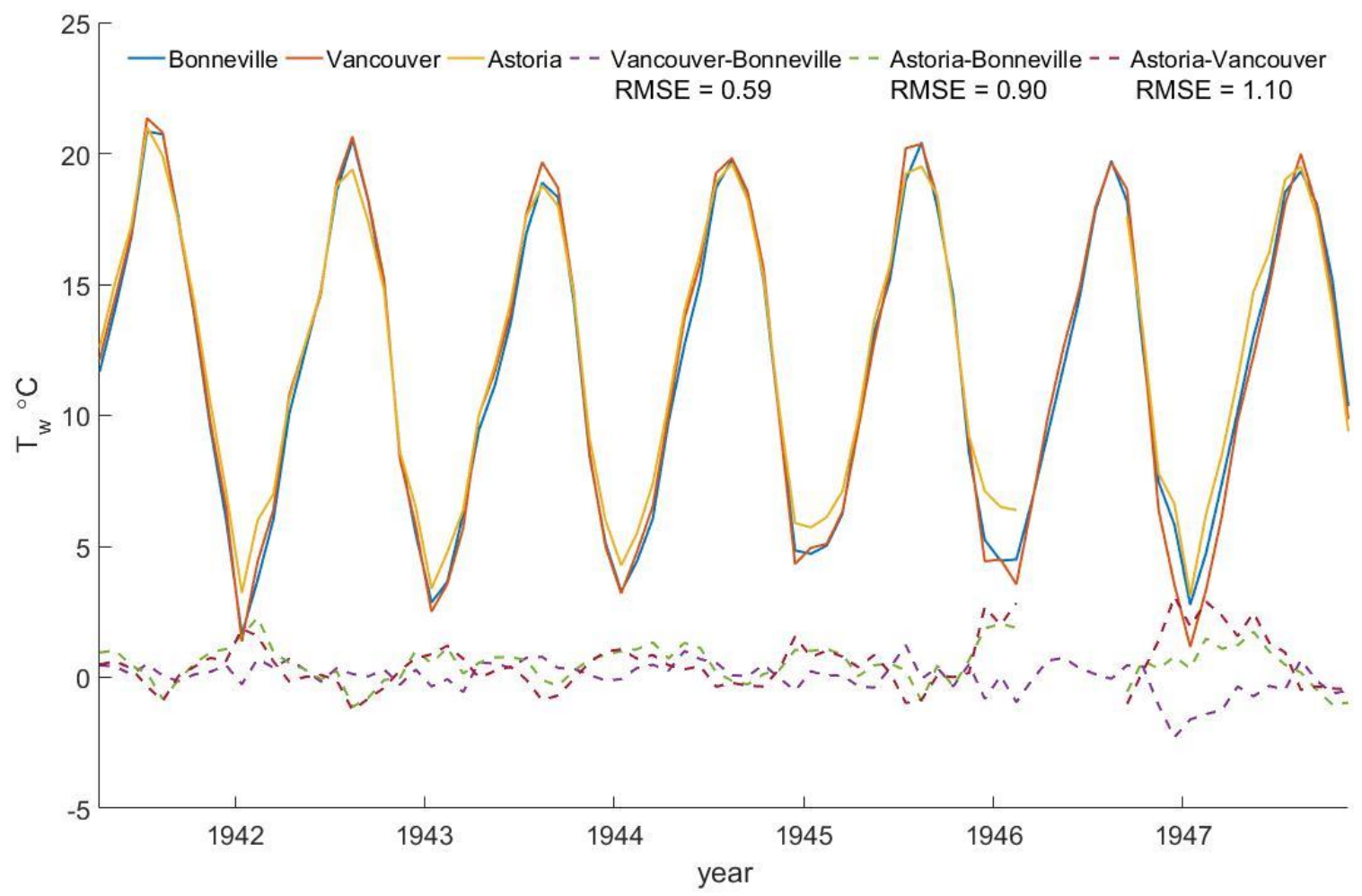

Figure 4. Monthly average water temperature $\left(T_{w}\right)$ measured at Bonneville Dam, Vancouver, and Astoria with residuals shown by dotted lines, 1941-1947.

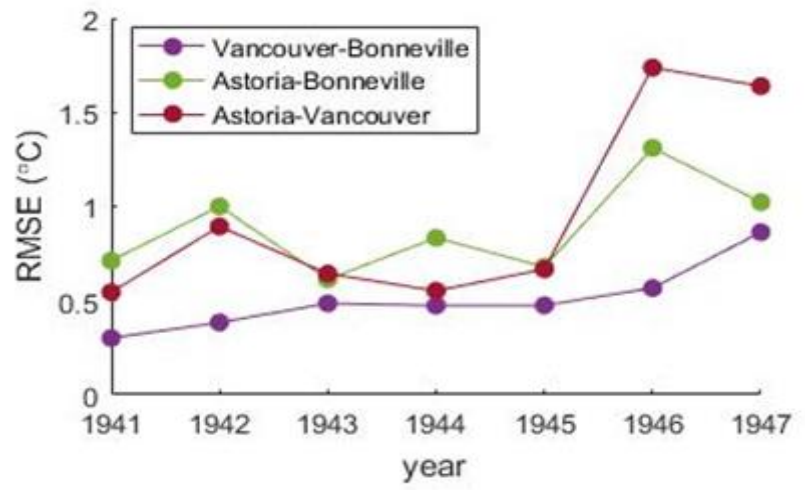

Figure 5. RMSE's between monthly average water temperature $\left(T_{w}\right)$ measured at Bonneville Dam, Vancouver, and Astoria, 1941-1947. 


\subsection{Climatology}

Climatological means of biweekly average $T_{w}$, air temperature $\left(T_{a}\right)$, and flow $(Q)$ were calculated for the modern and historical periods by taking the means of the biweekly averages for each twoweek period across each record span. For example, all biweekly average $T_{w}$ measurements with a reference date of January $7^{\text {th }}$ for the years 1938-1956 were averaged to obtain the historical climatological mean $T_{w}$ for that date. By comparing the climatological means for the historical and modern periods, long-term trends could be observed.

Climatology of biweekly average $T_{w}$ shows that annual maximum $T_{w}$ was $19.9^{\circ} \mathrm{C}$ on average during the historical period and $21.4^{\circ}$ during the modern period (Figure 6). During both periods, this maximum occurred in the middle of August. Springtime (March and April) $T_{w}$ did not change much between the two periods, while modern $T_{w}$ was at least $1.5^{\circ} \mathrm{C}$ higher on average in the summer and autumn months (between June and January). The greatest difference occurred during November, when $T_{w}$ was $2.6^{\circ} \mathrm{C}$ higher on average during the modern period.

Biweekly average $T_{a}$ did not change as much as $T_{w}$ between the two periods. January through March $T_{a}$ was $0.5^{\circ} \mathrm{C}$ to $1.8^{\circ} \mathrm{C}$ higher during the modern period, but during the rest of the year $T_{a}$ fluctuated between $0.7^{\circ} \mathrm{C}$ lower to $1.3^{\circ} \mathrm{C}$ higher during the modern period (Figure 7). Annual maximum $T_{a}$ occurred in late July during the historical period, but shifted to early August during the modern period. This may explain the apparent decrease in early July $T_{a}$, as the peak essentially shifted two weeks during the modern period.

Changes in $Q$ were very dramatic between the two periods due to the increase in dams and reservoir management in the modern period. Average annual maximum $Q$ decreased from close to 14,000 $\mathrm{m}^{3} / \mathrm{s}$ in the historical period to $8,000 \mathrm{~m}^{3} / \mathrm{s}$ in the modern period, while during November through March average $Q$ was 1,000 to $2,000 \mathrm{~m}^{3} / \mathrm{s}$ higher in the modern period (Figure 8 ). This change in the annual hydrograph shows the effects of storage dams, where water is held during periods of naturally high $Q$ and released later in order to optimize hydroelectric power generation and decrease risk of flooding. It is possible that long-term cycles such as the Pacific decadal oscillation also affected $Q$ during these periods (e.g., Naik and Jay, 2005; 2011). 
Figure 6. Climatological means of biweekly average water temperature $\left(\boldsymbol{T}_{w}\right)$ at Bonneville Dam for 1938-1956 and 1977-2003. Interquartile ranges (IQR's) show values between the first and third quartile in each data set. $\Delta T_{w}$ is the historical values subtracted from the modern values.

Figure 7. Climatological means of biweekly average air temperature $\left(T_{a}\right)$ for 1938-1956 and 1977-2003. Interquartile ranges (IQR's) show values between the first and third quartile in each data set. $\Delta T_{a}$ is the historical values subtracted from the modern values.

Figure 8. Climatological means of biweekly average discharge $(Q)$ at The Dalles for 19381956 and 1977-2003. Interquartile ranges (IQR's) show values between the first and third quartile in each data set. $\Delta Q$ is the historical values subtracted from the modern values.
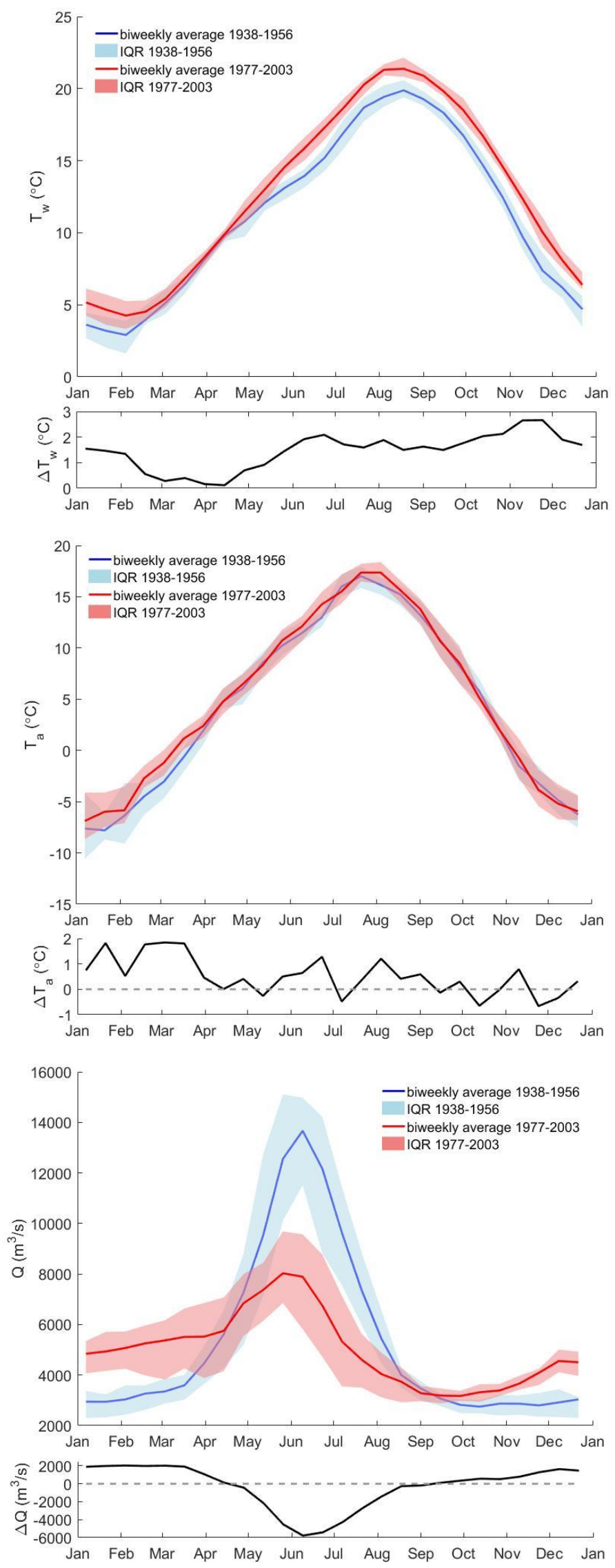


\subsection{Historical Period}

A simple way to test the efficacy of a statistical model (see results below) is to determine whether the model performs similarly to, or better than, climatology. Biweekly average $T_{w}$ measurements at Bonneville Dam for 1938-1956 had an RMSE of $1.16^{\circ} \mathrm{C}$ when compared to the climatological average for that period (Figure 9).

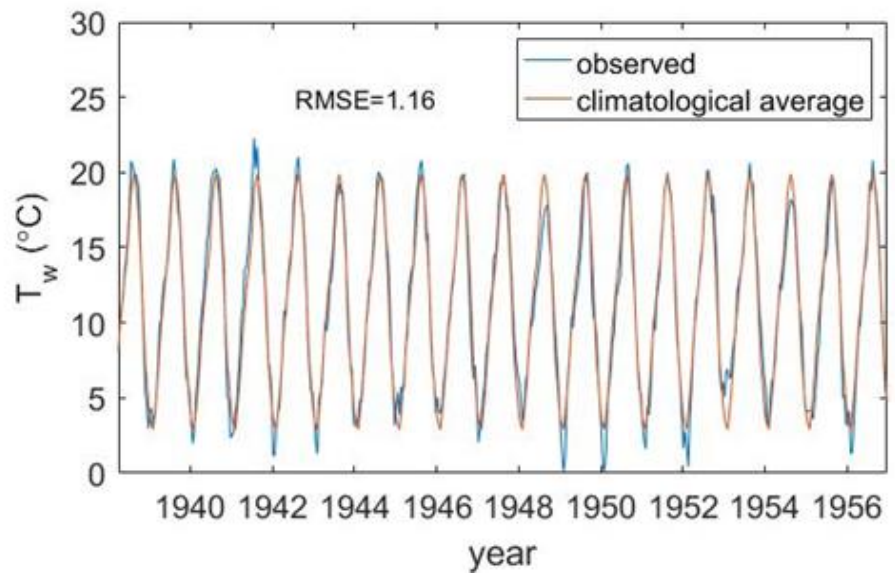

Figure 9. Comparison of biweekly average water temperature $\left(T_{w}\right)$ at Bonneville Dam to climatological average, 1938-1956.

To develop a statistical model of $T_{w}$ for

the historical period, different time lags were tested for $T_{a}$. A two-week time lag on $T_{a}$ was found to give the lowest RMSE. The lag probably occurs due to the travel time of water through the large Columbia River basin (Figure 1). Additionally, $T_{w}$ responds more slowly to atmospheric heating than $T_{a}$ due to its higher heat capacity.

Different combinations of six-month periods were also tested to develop seasonal regressions. Regressions using May through October (summer) and November through April (winter) produced the best results, as measured by the smallest RMSE. When $Q$ was included in both the summer and winter regressions, the coefficient had a negative sign during summer and a positive sign during winter (Table 1). To visually assess how $T_{w}$ was correlated with $Q, T_{a}$ was binned into 1 degree subsets (e.g., $8.5-9.5^{\circ} \mathrm{C}$ ), and scatter plots of $Q$ and $T_{w}$ were produced (Figures 10 and 11). Since a two-week time lag for $T_{a}$ was used in the models, the $T_{w}$ and $Q$ measurements that occurred two weeks after each subset of $T_{a}$ measurements were grouped together. Robust linear regression was used to determine the slope of the $T_{w} / Q$ relationship for each $T_{a}$-binned subset. During summer months the relationship was typically negative (mean slope $=-0.235{ }^{\circ} \mathrm{C} / 10^{3} \mathrm{~m}^{3} / \mathrm{s}$ ) as would be expected (Figure 10). During winter months the relationship was usually not significant (Figure 11), suggesting that a positive relationship between $T_{w}$ and $Q$ during winter was not statistically significant. 


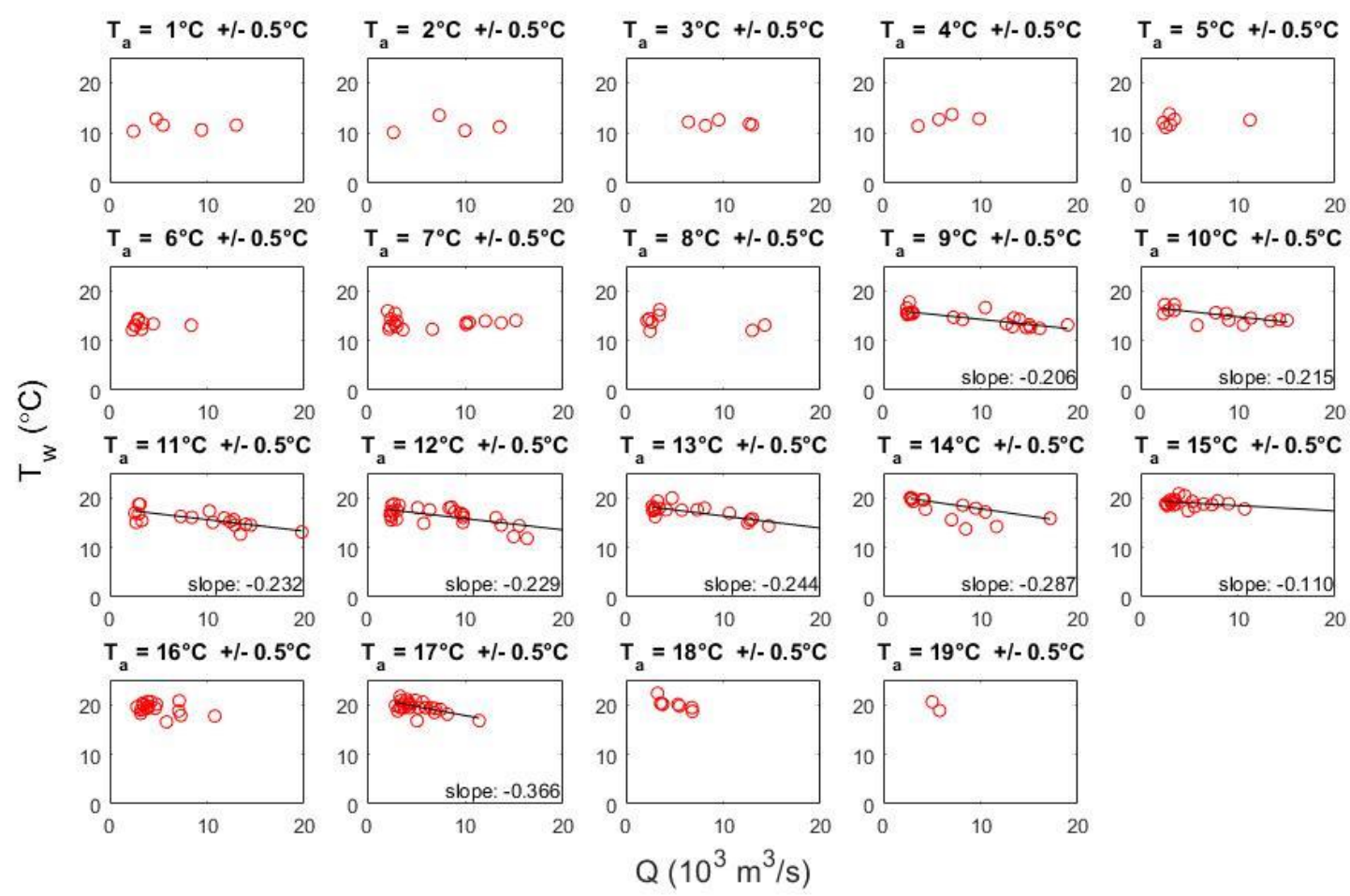

Figure 10. Comparison of relationships between biweekly average water temperature $\left(T_{w}\right)$ at Bonneville Dam and flow $(Q)$ at The Dalles at constant basin air temperature $\left(T_{a}\right)$ during May through October, 1938-1956. Slopes are shown where a significant relationship was found.
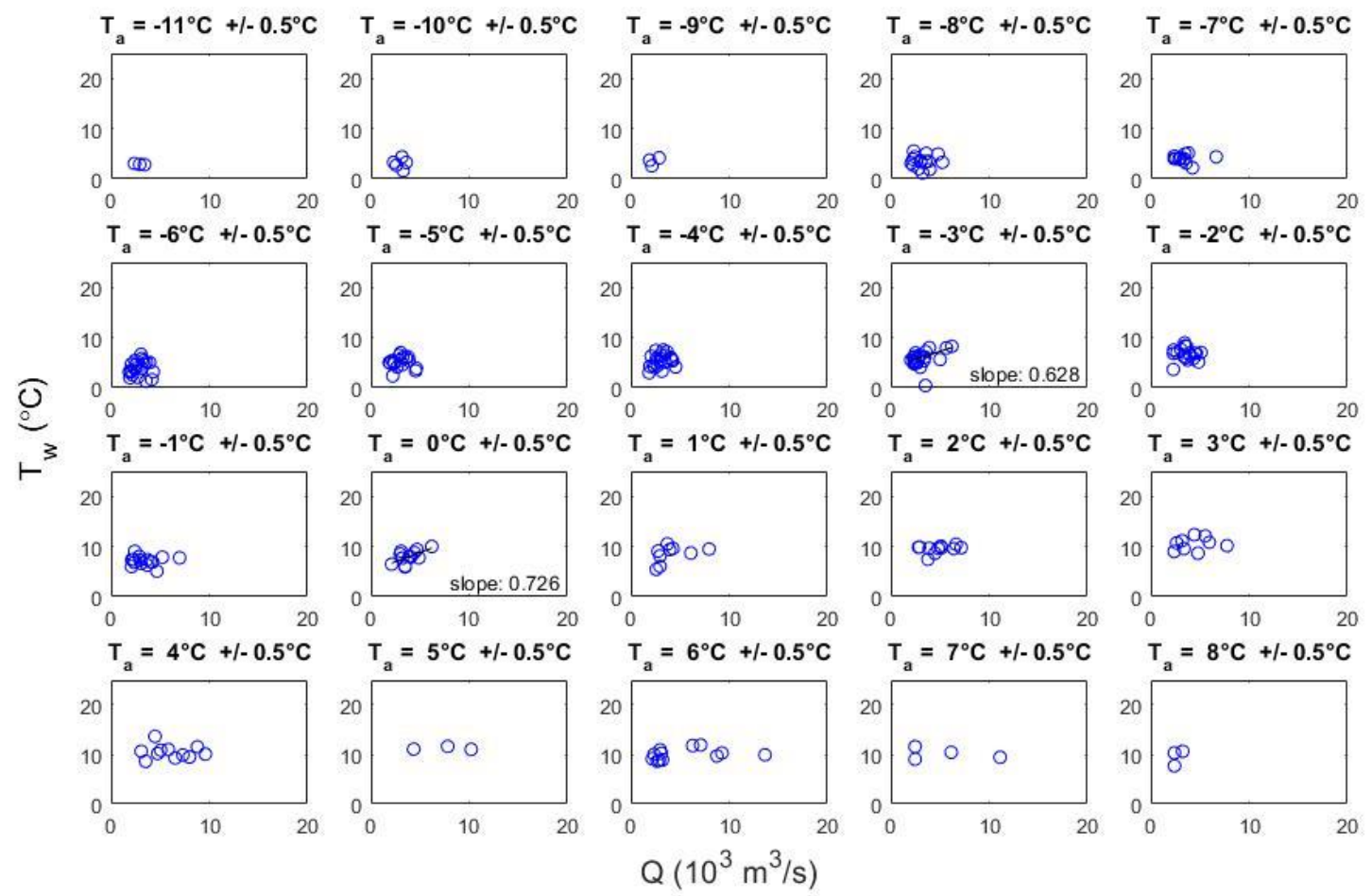

Figure 11. Comparison of relationships between biweekly average water temperature $\left(T_{w}\right)$ at Bonneville Dam and flow $(Q)$ at The Dalles at constant basin air temperature $\left(T_{a}\right)$ during November through April, 1938-1956. Slopes are shown where a significant relationship was found. 
Table 1. Regression coefficients for different water temperature models, 1938-1956.

\begin{tabular}{|l|c|c|c|c|c|}
\hline & \multirow{2}{*}{ Entire Year } & \multicolumn{2}{|c|}{ Seasonal } & \multicolumn{2}{c|}{ Seasonal without $Q$ in Winter } \\
\cline { 3 - 6 } & & May - Oct & Nov - Apr & May - Oct & Nov - Apr \\
\hline Constant $\left(\beta_{0}\right),{ }^{\circ} \mathrm{C}$ & $9.10+/-0.20$ & $11.40+/-0.49$ & $6.85+/-0.46$ & $11.40+/-0.49$ & $7.65+/-0.19$ \\
\hline$T_{a}$ coefficient $\left(\beta_{1}\right),{ }^{\circ} \mathrm{C} /{ }^{\circ} \mathrm{C}$ & $0.686+/-0.015$ & $0.539+/-0.033$ & $0.477+/-0.036$ & $0.539+/-0.033$ & $0.507+/-0.033$ \\
\hline$Q$ coefficient $\left(\beta_{2}\right),{ }^{\circ} \mathrm{C} / 10^{3} \mathrm{~m}^{3} / \mathrm{s}$ & $-0.155+/-0.032$ & $-0.187+/-0.032$ & $0.196+/-0.105$ & $-0.187+/-0.032$ & - \\
\hline
\end{tabular}

Comparing the relationship between $T_{w}$ and $Q$ for the whole data set showed that during summer months $T_{w}$ was high and $Q$ varied from high to low (Figure 12). Although the winter $T_{w} / Q$ relationship was generally not significant at constant $T_{a}$, there was a significant slope when all the points were considered together. During winter months $T_{w}$ and $Q$ were both generally below average. It is possible that the positive correlation between $T_{w}$ and $Q$ occurs because $T_{w}$ increases during spring and early summer at the same time that $Q$ is increasing. Figure 12 also shows that the $T_{w} / Q$ relationship

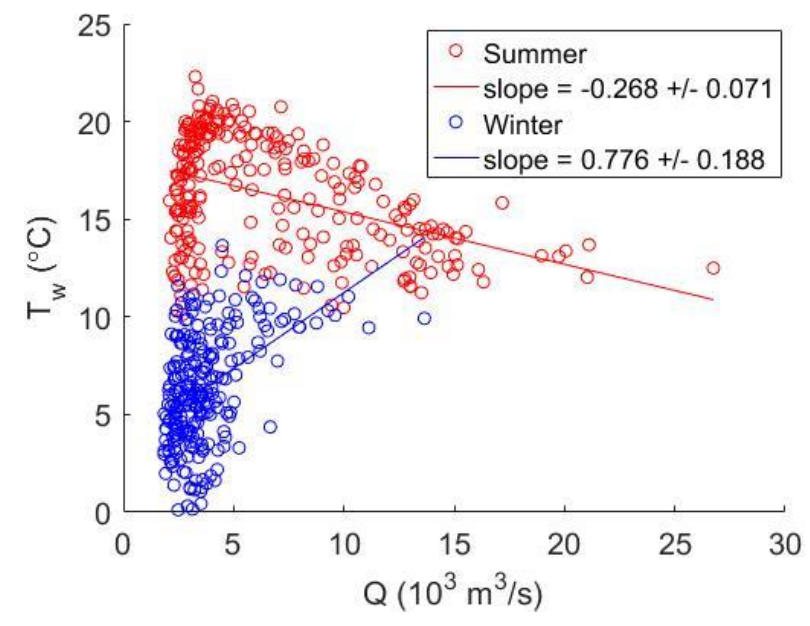

Figure 12. Comparison of relationship between biweekly average water temperature $\left(T_{w}\right)$ at Bonneville Dam and flow $(Q)$ at The Dalles for May through October (summer) and November through April (winter), 1938-1956.

is more pronounced when $Q$ is above 5,000 $\mathrm{m}^{3} / \mathrm{s}$, which occurs mainly during May through August. For these reasons, $Q$ was left out of the winter seasonal regression.

The final model selected for 1938-1956 was based on a regression for May through October (summer) using $T_{a}$ and $Q$ and a regression for November through April (winter) using only $T_{a}$ (Figure 13). For both regressions, $T_{a}$ was lagged by two weeks. This model had an RMSE of $1.22^{\circ} \mathrm{C}$, which is slightly lower than the RMSE of the model based on the entire year (Table 2). The model has a higher overall RMSE than the climatological average but a lower RMSE for maximum annual $T_{w}\left(0.74^{\circ} \mathrm{C}\right.$ versus $\left.1.02^{\circ} \mathrm{C}\right)$. The RMSE for summer was $1.20^{\circ} \mathrm{C}$, while for winter it was $1.33^{\circ} \mathrm{C}$. This indicates that the summer regression is more reliable than the winter regression, possibly due to a nonlinear relationship between $T_{w}$ and $T_{a}$ at sub-zero $T_{a}$. The model did not 
predict as well in years with unusual $T_{a}$ and $Q$. For example, it under-predicted high summer $T_{w}$ in 1941 when $T_{a}$ was exceptionally high. Similarly, the model over-predicted summer $T_{w}$ in 1948, coinciding with high $Q$ that year.

Table 2. RMSE's for different water temperature models, 1938-1956.

\begin{tabular}{|l|l|l|l|l|}
\hline & Entire Year & Seasonal & $\begin{array}{l}\text { Seasonal without } \\
Q \text { in Winter }\end{array}$ & Climatology \\
\hline RMSE,$~^{\circ} \mathrm{C}$ & 1.29 & 1.23 & 1.22 & 1.16 \\
\hline RMSE $_{\max },{ }^{\circ} \mathrm{C}$ & 0.73 & 0.74 & 0.74 & 1.02 \\
\hline
\end{tabular}

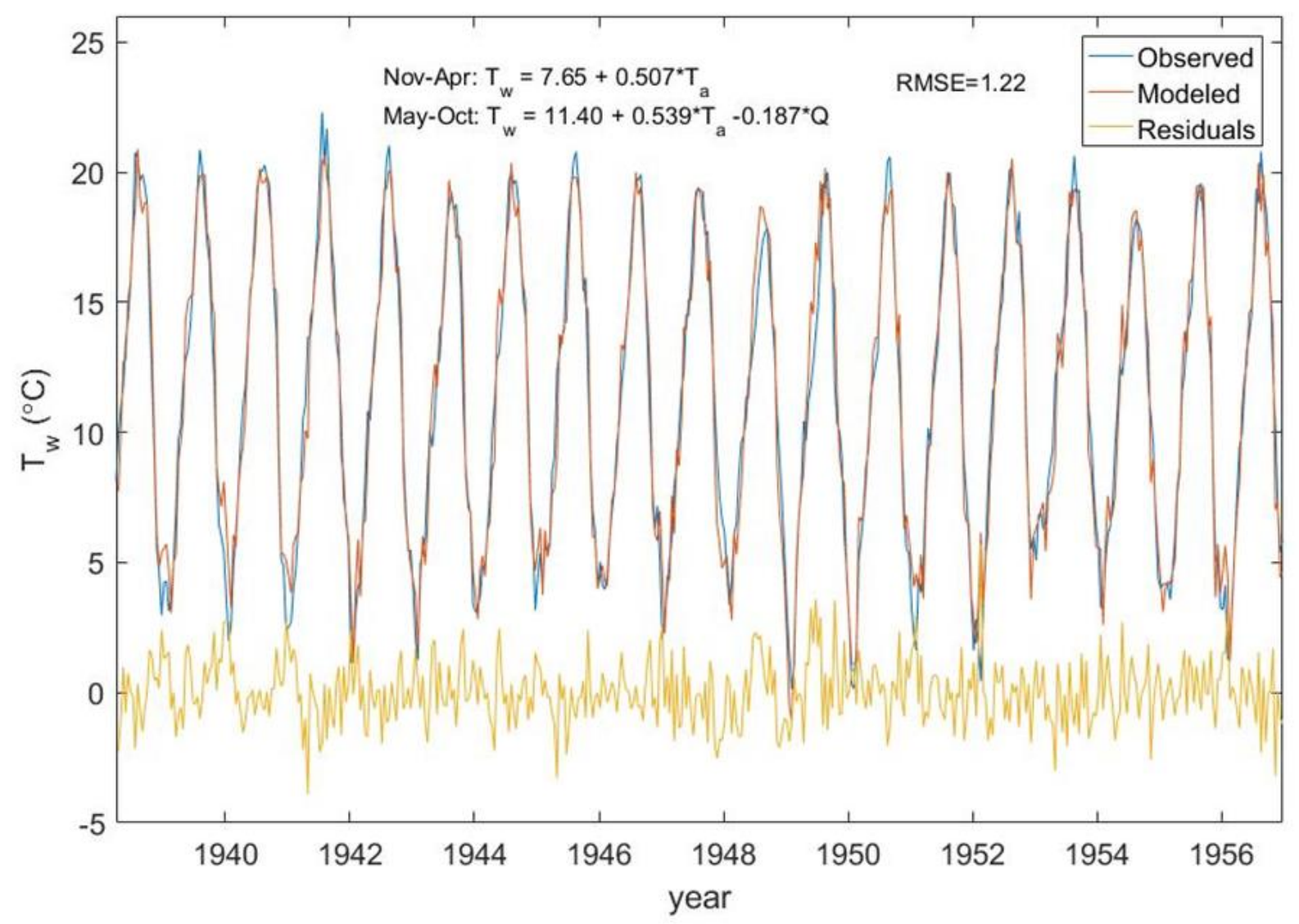

Figure 13. Modeled and observed biweekly average water temperature $\left(T_{w}\right)$ at Bonneville Dam, 1938-1956. Residuals show observed measurements subtracted from model results. 


\subsection{Modern Period}

Biweekly average $T_{w}$ measurements from Bonneville Dam for 1977-2003 were compared to the climatological average for that period, resulting in an RMSE of $1.02^{\circ} \mathrm{C}$ (Figure 14). The methodology described in section 3.3 was followed to develop a statistical model for this period, including verifying the relationship between $T_{w}$ and $Q$. Dividing the data seasonally gave a negative regression coefficient for $Q$ for November through April (winter) as well as May through October (summer) (Table 3). Isolating $T_{w}$ and $Q$ relationships at constant $T_{a}$ gave similar results as for the historical period. Slopes were negative (mean $=-0.390{ }^{\circ} \mathrm{C} / 10^{3} \mathrm{~m}^{3} / \mathrm{s}$ ) during summer (Figure 15) and generally insignificant in winter (Figure 16) indicating that a negative $Q$ coefficient in summer and no $Q$ coefficient in winter was accurate. When all $T_{w}$ and $Q$ points were plotted together, there was a negative slope during summer and an insignificant slope during winter (Figure 17). Similar to the historical period, there was a more clear relationship between $T_{w}$ and $Q$ when $Q$ was above $5,000 \mathrm{~m}^{3} / \mathrm{s}$.

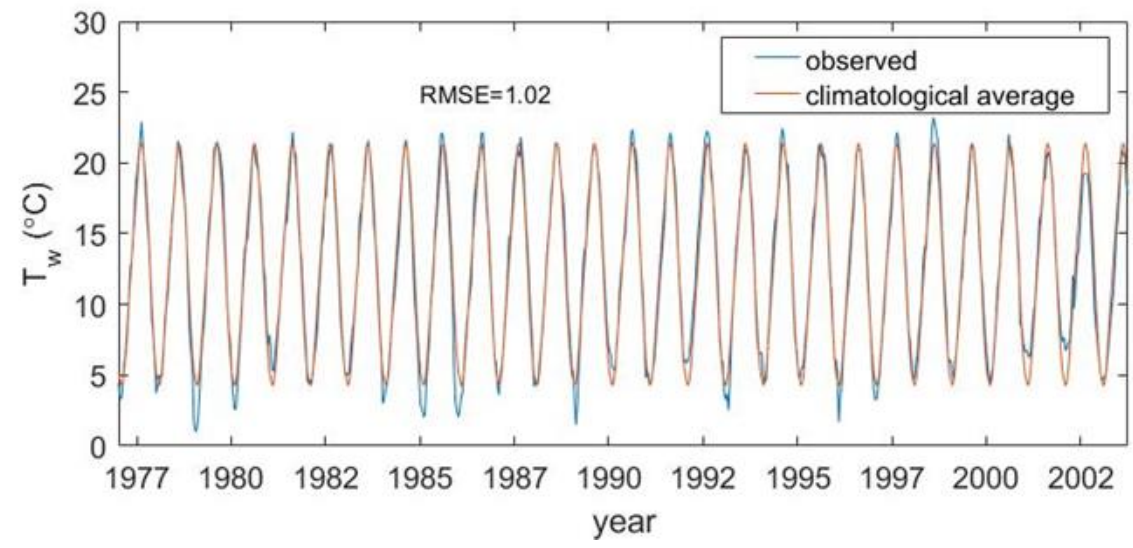

Figure 14. Comparison of biweekly average water temperature $\left(T_{w}\right)$ at Bonneville Dam to climatological average, 1977-2003.

Table 3. Regression coefficients for different water temperature models, 1977-2003.

\begin{tabular}{|l|c|c|c|c|c|}
\hline & \multirow{2}{*}{ Entire Year } & \multicolumn{2}{|c|}{ Seasonal } & \multicolumn{2}{c|}{ Seasonal without $Q$ in Winter } \\
\cline { 3 - 6 } & & May - Oct & Nov - Apr & May - Oct & Nov - Apr \\
\hline Constant $\left(\beta_{0}\right),{ }^{\circ} \mathrm{C}$ & $10.95+/-0.33$ & $13.89+/-0.47$ & $9.44+/-0.57$ & $13.89+/-0.47$ & $8.40+/-0.18$ \\
\hline$T_{a}$ coefficient $\left(\beta_{1}\right),{ }^{\circ} \mathrm{C} /{ }^{\circ} \mathrm{C}$ & $0.686+/-0.015$ & $0.483+/-0.026$ & $0.519+/-0.035$ & $0.483+/-0.026$ & $0.516+/-0.035$ \\
\hline$Q$ coefficient $\left(\beta_{2}\right),{ }^{\circ} \mathrm{C} / 10^{3} \mathrm{~m}^{3} / \mathrm{s}$ & $-0.319+/-0.059$ & $-0.318+/-0.052$ & $-0.201+/-0.105$ & $-0.318+/-0.052$ & - \\
\hline
\end{tabular}




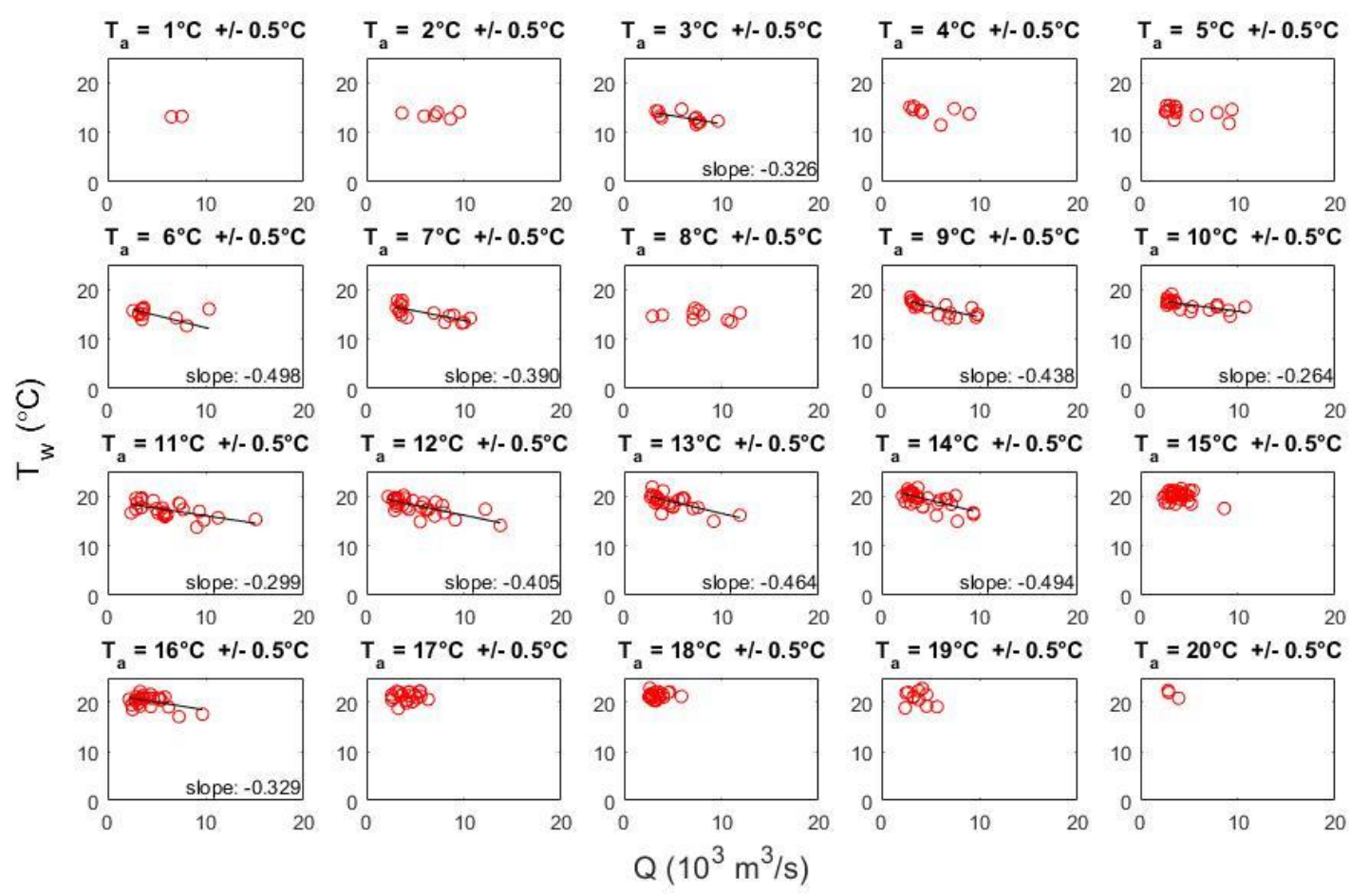

Figure 15. Comparison of relationships between biweekly average water temperature $\left(T_{w}\right)$ at Bonneville Dam and flow $(Q)$ at The Dalles at constant basin air temperature $\left(T_{a}\right)$ during May through October, 1977-2003. Slopes are shown where a significant relationship was found.
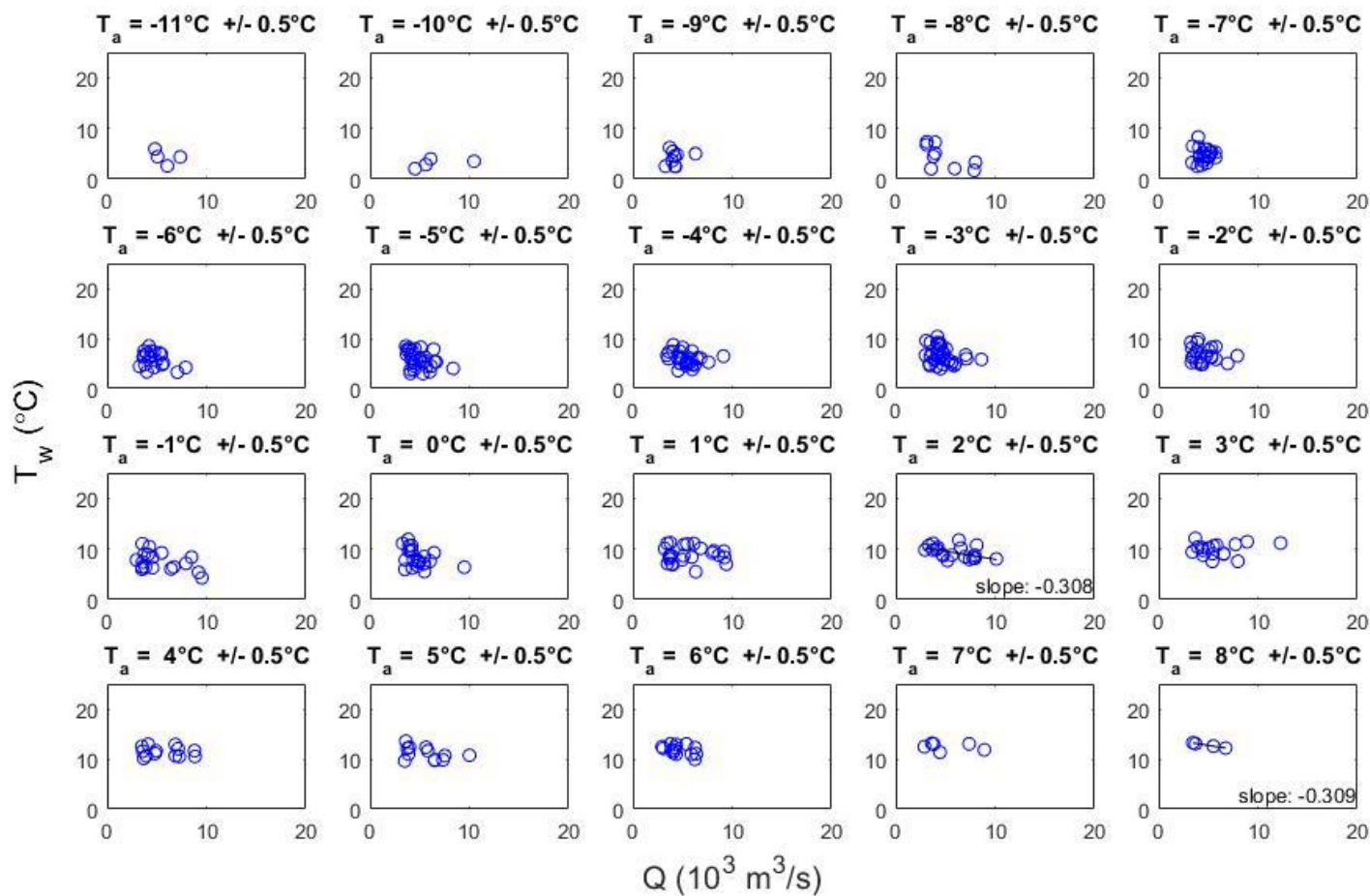

Figure 16. Comparison of relationships between biweekly average water temperature $\left(T_{w}\right)$ at Bonneville Dam and flow $(Q)$ at The Dalles at constant basin air temperature $\left(T_{a}\right)$ during November through April, 1977-2003. Slopes are shown where a significant relationship was found. 
Figure 17. Comparison of relationship between biweekly average water temperature $\left(T_{w}\right)$ at Bonneville Dam and flow $(Q)$ at The Dalles for May through October (summer) and November through April (winter), 1977-2003.

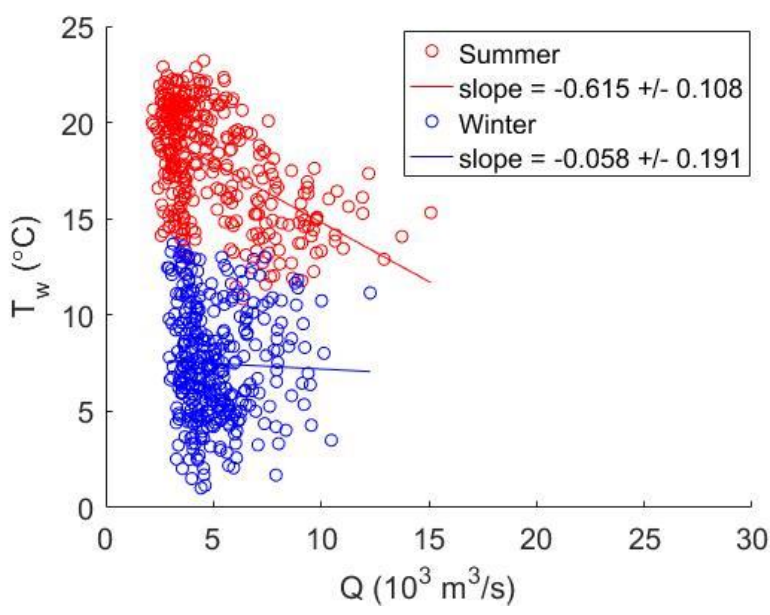

While it did not have the lowest RMSE, the final model chosen for the modern period had the same form and predictor variables as the one chosen for the historical period so that the two could be compared. $T_{a}$ was lagged by two weeks and separate regressions were performed for May through October and November through April, with $Q$ only included as a predictor variable in May through October (Figure 18). This model had an overall RMSE of $1.43^{\circ} \mathrm{C}$, which was higher than the RMSE of $1.02^{\circ} \mathrm{C}$ obtained by using the climatological average (Table 4). The annual maximum $T_{w}$ RMSE was also higher $\left(0.94^{\circ} \mathrm{C}\right.$ versus $\left.0.81^{\circ} \mathrm{C}\right)$. While the statistical model is not as accurate overall as the climatological model, it better captures interannual variability. The summer regression had an RMSE of $1.11^{\circ} \mathrm{C}$, while the winter regression had an RMSE of $1.48^{\circ} \mathrm{C}$. This is similar to the historical model and may reflect the non-linear relationship between $T_{w}$ and $T_{a}$ at sub-zero $T_{a}$.

Table 4. Comparison of RMSE's for different water temperature models for 1977-2003.

\begin{tabular}{|l|l|l|l|l|}
\hline & Entire Year & Seasonal & $\begin{array}{l}\text { Seasonal without } \\
Q \text { in Winter }\end{array}$ & Climatology \\
\hline RMSE, $^{\circ} \mathrm{C}$ & 1.53 & 1.39 & 1.43 & 1.02 \\
\hline RMSE $_{\max }{ }^{\circ} \mathrm{C}$ & 1.30 & 0.94 & 0.94 & 0.81 \\
\hline
\end{tabular}




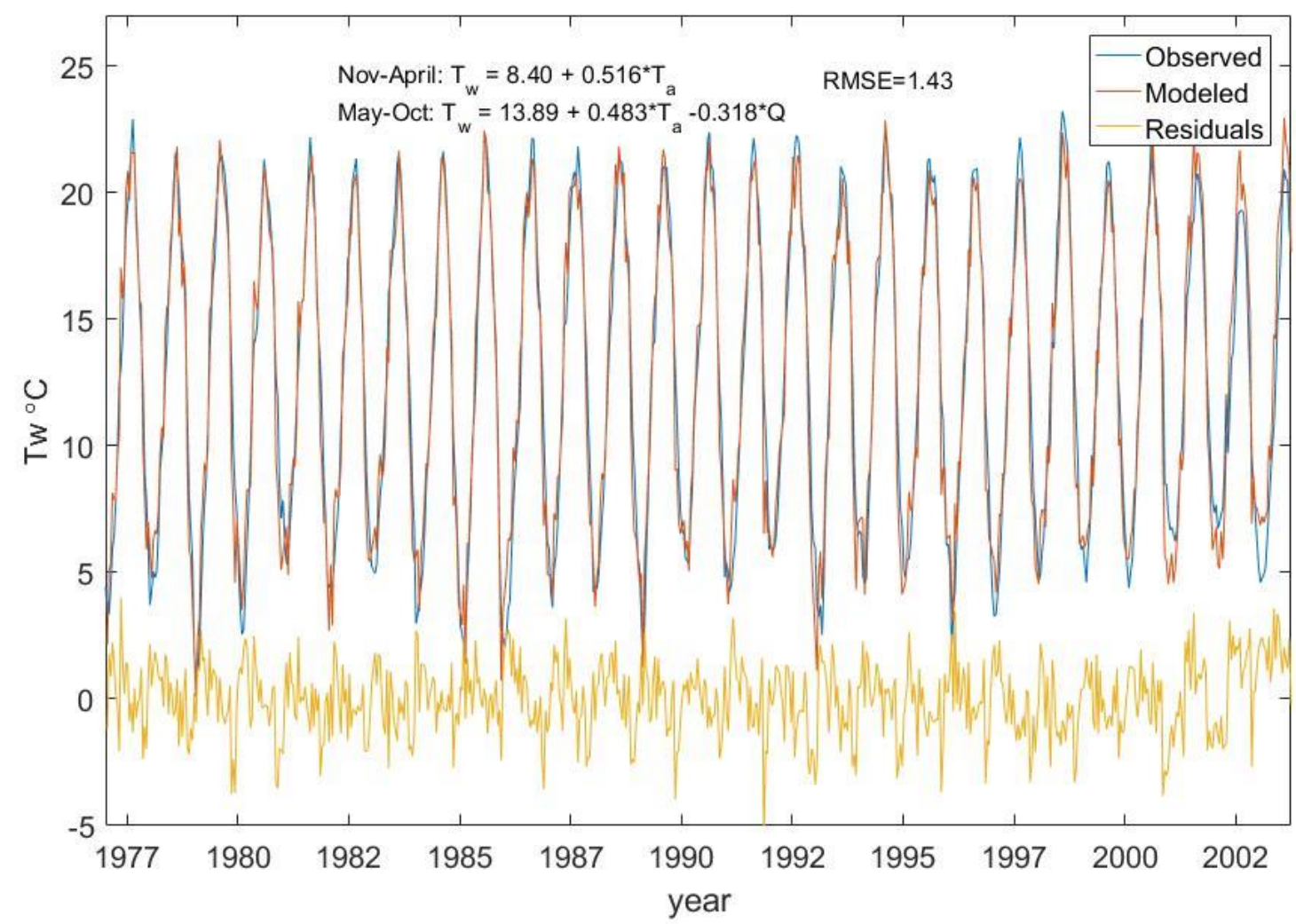

Figure 18. Modeled and observed biweekly average water temperature $\left(T_{w}\right)$ at Bonneville Dam, 1977-2003. Residuals show observed measurements subtracted from model results.

\subsection{Comparison}

The historical and modern statistical models depend on three regression coefficients and two input variables, all of which can change over decadal and secular time scales as the heat balance and hydrology shift (Equations 3 and 4). Any long-term trends in $T_{a}$ due to climate change produce altered $T_{w}$ in the statistical model. By the same mechanism, changed summertime (May through October) $Q$ will cause a shift in modeled $T_{w}$. The regression coefficients for $T_{a}$ and $Q$ denote the sensitivity of the river system to these parameters; any changes to these coefficients likely reflect changes to physical characteristics such as the mean residence time of a water parcel, the mean depth of the system, the amount of shading in riparian streams, or any other factors which affect the advection-diffusion equation (Equation 1).

A comparison of the $T_{a}$ coefficients $\left(\beta_{1}\right)$ for the historical and modern models (Equation 3 ) shows that the modeled $T_{w} / T_{a}$ relationship in winter did not change significantly, whereas the modeled $T_{w} / T_{a}$ relationship decreased significantly in summer from $0.539{ }^{\circ} \mathrm{C} /{ }^{\circ} \mathrm{C}$ to $0.483{ }^{\circ} \mathrm{C} /{ }^{\circ} \mathrm{C}$ (Table 5 ). A similar decrease in sensitivity over time is also observed in the response of $T_{w}$ data to a $T_{a}$ 
perturbation from climatology (such as a heat wave). During the historical period, a $1^{\circ} \mathrm{C}$ anomaly in $T_{a}$ from climatology corresponded to a $\sim 0.30^{\circ} \mathrm{C}$ anomaly in $T_{w}$ from climatology (Figure 19). During the modern period, the same $T_{a}$ anomaly corresponded to a $\sim 0.23^{\circ} \mathrm{C}$ anomaly in $T_{w}$ (Figure 20). The differences in the $T_{w} / T_{a}$ relationships between the historical and modern models and data indicate that the modern hydrological system has become less responsive to recent (two weeks prior) atmospheric heating and cooling in the basin, especially during summer months. It is possible that the system responsiveness to earlier atmospheric forcing has increased, but this has not yet been investigated.

The $Q$ coefficient $\left(\beta_{2}\right)$ increased dramatically in magnitude from $-0.187{ }^{\circ} \mathrm{C} / 10^{3} \mathrm{~m}^{3} / \mathrm{s}$ to $0.318^{\circ} \mathrm{C} / 10^{3} \mathrm{~m}^{3} / \mathrm{s}$ for the summertime model (Table 5). While this may indicate that $Q$ produced a greater effect on $T_{w}$ during the modern period, the change may also (in part)

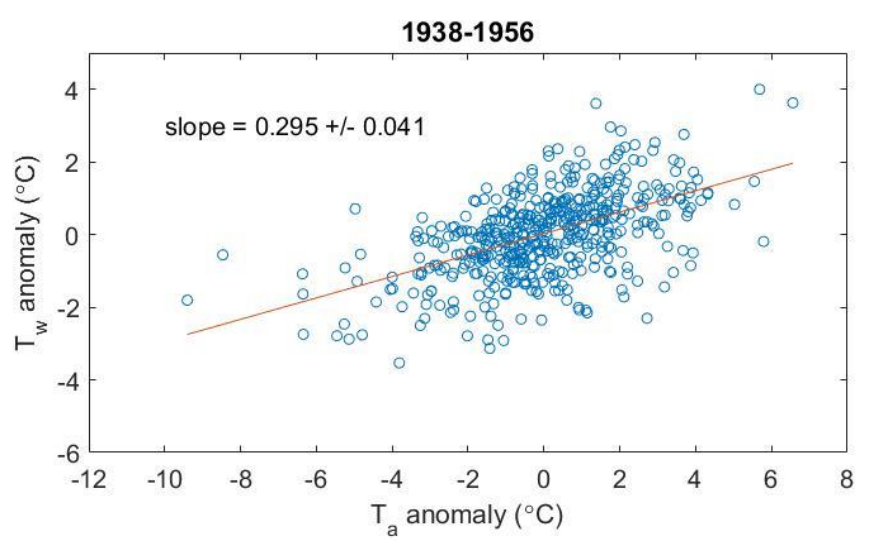

Figure 19. Measured water temperature $\left(T_{w}\right)$ at Bonneville Dam deviation from climatological mean compared to measured basin air temperature $\left(T_{a}\right)$ deviation from climatological mean, 1938-1956.

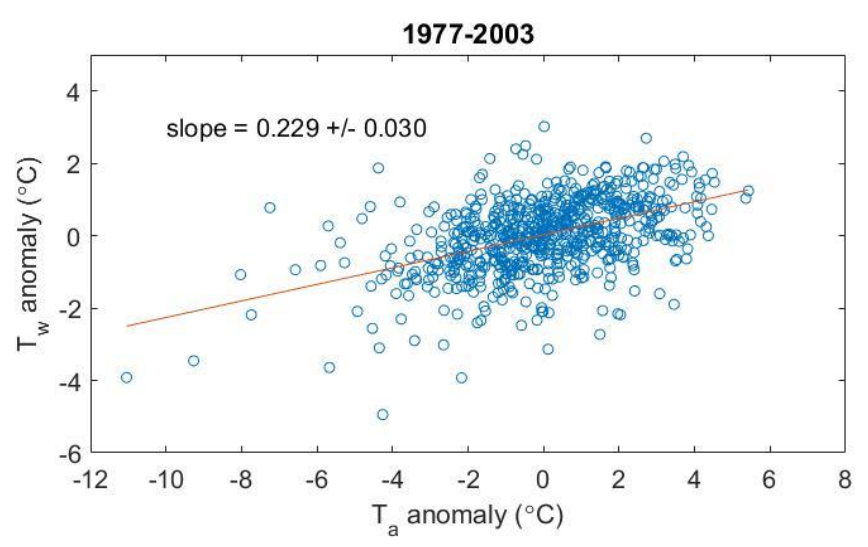

Figure 20. Measured water temperature $\left(T_{w}\right)$ at Bonneville Dam deviation from climatological mean compared to measured basin air temperature $\left(T_{a}\right)$ deviation from climatological mean, 1977-2003. reflect an artifact of the regression. Because the dynamic range of $Q$ was much lower during the modern period, any non-linearity in the $T_{w} / Q$ relationship will be represented differently. In particular, as noted earlier, the sensitivity of $T_{w}$ to $Q$ appears to lessen (asymptote) during historical flood events such as 1948 (e.g., Figure 12). Therefore, the regression slope in Figure 12 would steepen if the analysis were confined to the same range of $Q$ as Figure 17, i.e., if restricted to less than $15,000 \mathrm{~m}^{3} / \mathrm{s}$. 
Table 5. Change in regression coefficients for 1938-1956 and 1977-2003.

\begin{tabular}{|l|r|r|r|r|}
\hline & Historical Period & Modern Period & Difference & p-value \\
\hline$T_{a}$ Coefficient-Summer $\left(\beta_{1}\right),{ }^{\circ} \mathrm{C} /{ }^{\circ} \mathrm{C}$ & $0.539+/-0.033$ & $0.483+/-0.026$ & -0.056 & 0.01 \\
\hline$T_{a}$ Coefficient-Winter $\left(\beta_{1}\right),{ }^{\circ} \mathrm{C} /{ }^{\circ} \mathrm{C}$ & $0.507+/-0.033$ & $0.516+/-0.035$ & +0.009 & 1.29 \\
\hline$Q$ coefficient-Summer $\left(\beta_{2}\right),{ }^{\circ} \mathrm{C} / 10^{3} \mathrm{~m}^{3} / \mathrm{s}$ & $-0.187+/-0.032$ & $-0.318+/-0.052$ & -0.135 & 0.00 \\
\hline$T_{w}$ anomaly vs. $T_{a}$ anomaly, ${ }^{\circ} \mathrm{C} /{ }^{\circ} \mathrm{C}$ & $0.295+/-0.041$ & $0.229+/-0.030$ & -0.067 & 0.01 \\
\hline
\end{tabular}

The changes in biweekly average $Q$ were much greater than the changes in $T_{a}$ between the two periods (Figures 7 and 8), suggesting that changes in $Q$ might better explain the changes in $T_{w}$. Decreases in summer $Q$ are due in part to irrigation withdrawals and in part to storage reservoirs which hold water for later release (e.g., Naik and Jay, 2005; 2011). Storing water in these reservoirs allows it to heat more than under natural flow conditions due to an increased residence time. Moreover, an increased residence time implies that meteorological conditions can affect $T_{w}$ over a longer time period. This observation can help explain the decrease in the regression coefficient $\beta_{1}$ for two-week-lagged $T_{a}$. (Table 5). Essentially, storage reservoirs act as heat capacitors that store heated $T_{w}$ in the summer and slowly release it in autumn. This can be seen in the large increase in $T_{w}$ during October and November in the modern period (Figure 6).

Another indicator of the effect of river management on $T_{w}$ is the decrease in $T_{w}$ deviation from climatology. During the historical period, the RMSE of observed $T_{w}$ compared to climatology was $1.16^{\circ} \mathrm{C}$ (Figure 9), while during the modern period it was $1.02^{\circ} \mathrm{C}$ (Figure 14). The historical system was more natural and showed more variability, while the modern system is less variable, probably because dams and river management average out and dampen natural variability. Though it is possible that long-term improvements or changes in $T_{w}$ measurement protocol reduce the measured variance, initial analysis suggests this is a relatively small factor. Indeed, as shown in Table 5, the confidence intervals in the regression coefficients are small, and the coefficients $\beta_{1}$ are significantly different in the historical and modern models.

Overall, an excellent agreement is found between modeled and measured changes in $T_{w}$. The modeled change is defined as

$$
\Delta T_{w}=T_{w, M}-T_{w, H}
$$

where $T_{w, M}$ is $T_{w}$ predicted by the modern model with modern climatology as inputs, and $T_{w, H}$ is $T_{w}$ predicted by the historical model with historical climatology as inputs. Based on Equation 9, 
annual maximum $T_{w}$ increased by $1.5^{\circ} \mathrm{C}$. This matches the observed change of $1.5^{\circ} \mathrm{C}$, indicating that the models accurately represent the change in annual maximum $T_{w}$ over time.

The factors producing the modeled $1.5^{\circ} \mathrm{C}$ increase in annual maximum $T_{w}$ are next investigated by considering the individual contributions of changed $Q, T_{a}$, and regression coefficients.

These terms in Equation 9 are first expanded by substituting Equation 4, such that

$$
\Delta T_{w}=\left(\beta_{0, M}+\beta_{1, M} T_{a, M}+\beta_{2, M} Q_{M}\right)-\left(\beta_{0, H}+\beta_{1, H} T_{a, H}+\beta_{2, H} Q_{H}\right)
$$

where the subscripts $M$ and $H$ denote the modern and historical model coefficients ( $\beta$ terms) or climatology ( $Q$ and $T_{a}$ terms).

Rearranging Equation 10 gives

$$
\Delta T_{w}=\beta_{0, M}-\beta_{0, H}+\beta_{1, M} T_{a, M}-\beta_{1, H} T_{a, H}+\beta_{2, M} Q_{M}-\beta_{2, H} Q_{H}
$$

Based on the relationship between historical and modern coefficients and variables, Equation 11 can be written

$\Delta T_{w}=\Delta \beta_{0}+\left(\beta_{1, H}+\Delta \beta_{1}\right)\left(T_{a, H}+\Delta T_{a}\right)-\beta_{1, H} T_{a, H}+\left(\beta_{2, H}+\Delta \beta_{2}\right)\left(Q_{H}+\Delta Q\right)-\beta_{2, H} Q_{H}$

where the $\Delta$ terms denote the change (difference) between modern and historical conditions. For example, $\Delta \beta_{2}=\beta_{2, M}-\beta_{2, H}$.

After expanding Equation 12, the total change in modeled $T_{w}$ becomes a function of 7 terms:

$$
\Delta T_{w}=\underbrace{\Delta \beta_{0}}_{1}+\underbrace{\Delta \beta_{1} T_{a, H}}_{2}+\underbrace{\Delta \beta_{1} \Delta T_{a}}_{3}+\underbrace{\beta_{1, H} \Delta T_{a}}_{4}+\underbrace{\Delta \beta_{2} Q_{H}}_{5}+\underbrace{\Delta \beta_{2} \Delta Q}_{6}+\underbrace{\beta_{2, H} \Delta Q}_{7}
$$

In the equation above, terms 3 and 4 are influenced by changing $T_{a}$, terms 6 and 7 are influenced by changing $Q$, and terms $2,3,5$, and 6 are influenced by altered system management and changing system characteristics. The $\beta_{o}$ term is a fitting parameter in Equation 4 which represents (mathematically) the estimated $T_{w}$ in the extreme case of no $Q$ and zero $T_{a}$ at a two-week time lag. Practically, the $\beta_{o}$ term represents factors that are not being modeled (such as $T_{a}$ or $Q$ at a fourweek lag). A change in summertime $\beta_{o}$ (i.e., term 1) therefore reflects a change in the baseline 
system properties and system response that are not modeled by the other terms. Estimated values for the 7 terms in Equation 13 are given in Table 6 for the August time frame, corresponding to the time of peak $T_{w}$.

Table 6. Calculated values of the individual variables in Equation 13, representing August conditions during the time period of annual maximum water temperature $\left(T_{w, \max }\right)$.

\begin{tabular}{|c|c|c|c|c|c|c|c|c|}
\hline$\Delta \beta_{0}$ & $\beta_{1, H}$ & $\Delta \beta_{1}$ & $\beta_{2, H}$ & $\Delta \beta_{2}$ & $T_{a, H}$ & $\Delta T_{a}$ & $Q_{H}$ & $\Delta Q$ \\
\hline $2.5^{\circ} \mathrm{C}$ & $0.54^{\circ} \mathrm{C} /{ }^{\circ} \mathrm{C}$ & $-0.06^{\circ} \mathrm{C} /{ }^{\circ} \mathrm{C}$ & $-0.19^{\circ} \mathrm{C} / 10^{3} \mathrm{~m}^{3} / \mathrm{s}$ & $-0.14^{\circ} \mathrm{C} / 10^{3} \mathrm{~m}^{3} / \mathrm{s}$ & $17^{\circ} \mathrm{C}$ & $0.4^{\circ} \mathrm{C}$ & $5.410^{3} \mathrm{~m}^{3} / \mathrm{s}$ & $-1.710^{3} \mathrm{~m}^{3} / \mathrm{s}$ \\
\hline
\end{tabular}

Table 7. Calculated values of terms in Equation 12 based on values in Table 6 showing contribution from each term to total modeled change in water temperature $\left(T_{w}\right)$.

\begin{tabular}{|l|r|r|r|r|r|r|r|}
\hline \multirow{3}{*}{ Term } & 1 & 2 & 3 & \multicolumn{1}{c|}{4} & \multicolumn{1}{c|}{5} & \multicolumn{1}{c|}{6} & 7 \\
\cline { 2 - 8 } & \multicolumn{1}{c|}{$\Delta \beta_{0}$} & $\Delta \beta_{1} T_{a, H}$ & $\Delta \beta_{1} \Delta T_{a}$ & $\beta_{1, H} \Delta T_{a}$ & $\Delta \beta_{2} Q_{H}$ & \multicolumn{1}{c|}{$\Delta \beta_{2} \Delta Q$} & \multicolumn{1}{c|}{$\beta_{2, H} \Delta Q$} \\
\hline Value, ${ }^{\circ} \mathrm{C}$ & 2.5 & -0.95 & -0.02 & 0.19 & -0.73 & 0.23 & 0.32 \\
\hline
\end{tabular}

Overall, a relatively small portion of the $1.5^{\circ} \mathrm{C}$ increase in maximum $T_{w}$ since the mid-20 $0^{\text {th }}$ century is directly attributable to $T_{a}$ increases occurring at a two-week time lag (Table 7). Annual maximum $T_{\mathrm{a}}$ only increased by $0.4^{\circ} \mathrm{C}$, which, by the statistical model, suggests a roughly $0.2^{\circ} \mathrm{C}$ increase in $T_{w}$ (Table 7, term 4). The effect of the altered regression coefficient is even smalleran insignificant difference of roughly $0.02^{\circ} \mathrm{C}$ is obtained when the $T_{a}$ change of $0.4^{\circ} \mathrm{C}$ is scaled by the modern and historical $\beta_{1}$ coefficient (Table 7, term 3). These considerations suggest that slightly more than $10 \%(\sim 12 \%)$ of the increase in summer $T_{w}$ between the historical and modern periods was directly caused by climate change (Table 7, terms 3 and 4). Presumably, a comparison over a longer time scale might show a larger effect; this is left for a future study.

The direct effect of a changing hydrograph (at zero time lag) on peak $T_{w}$ is also modeled to be a relatively modest $0.32^{\circ} \mathrm{C}$ (Table 7, term 7). When the effect of both $\Delta Q$ terms in Equation 13 are considered (terms 6 and 7), the direct contribution of an altered hydrograph to changing peak $T_{w}$ is estimated to be $\sim 0.55^{\circ} \mathrm{C}$, or roughly $35 \%$ of total change (Table 7, terms 6 and 7). The relatively small, directly modeled influence occurs primarily because the measured difference in $Q$ between the historical and modern periods $\left(1,700 \mathrm{~m}^{3} / \mathrm{s}\right.$, Table 6$)$ is relatively small during late summer. By contrast, the dramatically reduced hydrograph in May and June produces an increase of up to $\sim 1.1^{\circ} \mathrm{C}$ on modeled $T_{w}$ (Figure 7 ). Given the relatively long residence time of water in the system, 
such changes may be influencing August $T_{w}$ and may be folded into the change observed in the $\beta_{o}$ coefficient (Table 7, term 1). More research is necessary on the influence of earlier time periods on measured data.

A comparison of the historical and modern models shows that the combined effects of changes in $Q$ as well as regression coefficients accounts for nearly $90 \%(88 \%)$, or $1.3^{\circ} \mathrm{C}$, of the change in annual maximum $T_{w}$ (Table 7, terms 1,2,5,6, and 7), although this is likely an overestimate because term 1 may reflect (in part) meteorological forcing at a larger time lag than two-weeks. Nonetheless, the overall small change in $T_{a}$ climatology over the time periods considered here (Figure 7) and the discussion above suggests that climate change is likely a small influence. System changes, as well as alterations to $Q$, therefore likely drive change to $T_{w}$ over the analyzed time period. However, while much of the long-term change in $Q$ is likely due to dams and river management, some portion may be attributable to climate change and climate variability. The changes in $Q$ between the two periods could be a result of changes in snowpack and precipitation in addition to reservoir management and irrigation withdrawals; therefore, a portion of the changed $Q$ could also represent climate change (Naik and Jay, 2005; 2011). The changes in regression coefficients reflect the influence of reservoir management, since water responds differently to atmospheric heating and cooling in the modern, managed system. Changes in riparian shading and other factors are also likely important.

Overall, a modeled increase of $1.3^{\circ} \mathrm{C}$ in maximum summertime $T_{w}$ due to altered $Q$ and reservoir management is higher than the $0.8^{\circ} \mathrm{C}$ increase in summer $T_{w}$ attributed to these factors by Bottom et al. (2011). Since some effect of climate change is included in the change in $Q$ and $\beta_{o}$ (Equation 4) the results are broadly consistent and support the conclusion that anthropogenic interventions into the system have dominated system changes since the mid- $20^{\text {th }}$ century. Nonetheless, as in Bottom et al. (2011), this result is approximate since some dams existed during the base period for the historical model. 


\subsection{Hindcasting}

To estimate trends over climate-change relevant time scales and elucidate natural variability, it would be useful to extend the $T_{w}$ record to pre-1938 conditions. Therefore, the historical model was used to hindcast $T_{w}$ at Bonneville dam for 1915-1938, using the available $Q$ and $T_{a}$ data as inputs. Monthly average $T_{w}$ measurements from Astoria from 1925-1938 were used to evaluate and ground-truth the statistical model results. Comparison of modeled $T_{w}$ at Bonneville Dam to measured $T_{w}$ at Astoria resulted in an RMSE of $1.69^{\circ} \mathrm{C}$ (Figure 21). This is $0.43^{\circ} \mathrm{C}$ higher than the RMSE of measured monthly average $T_{w}$ at Bonneville Dam compared to Astoria for 1938-1956 (Figure 2).

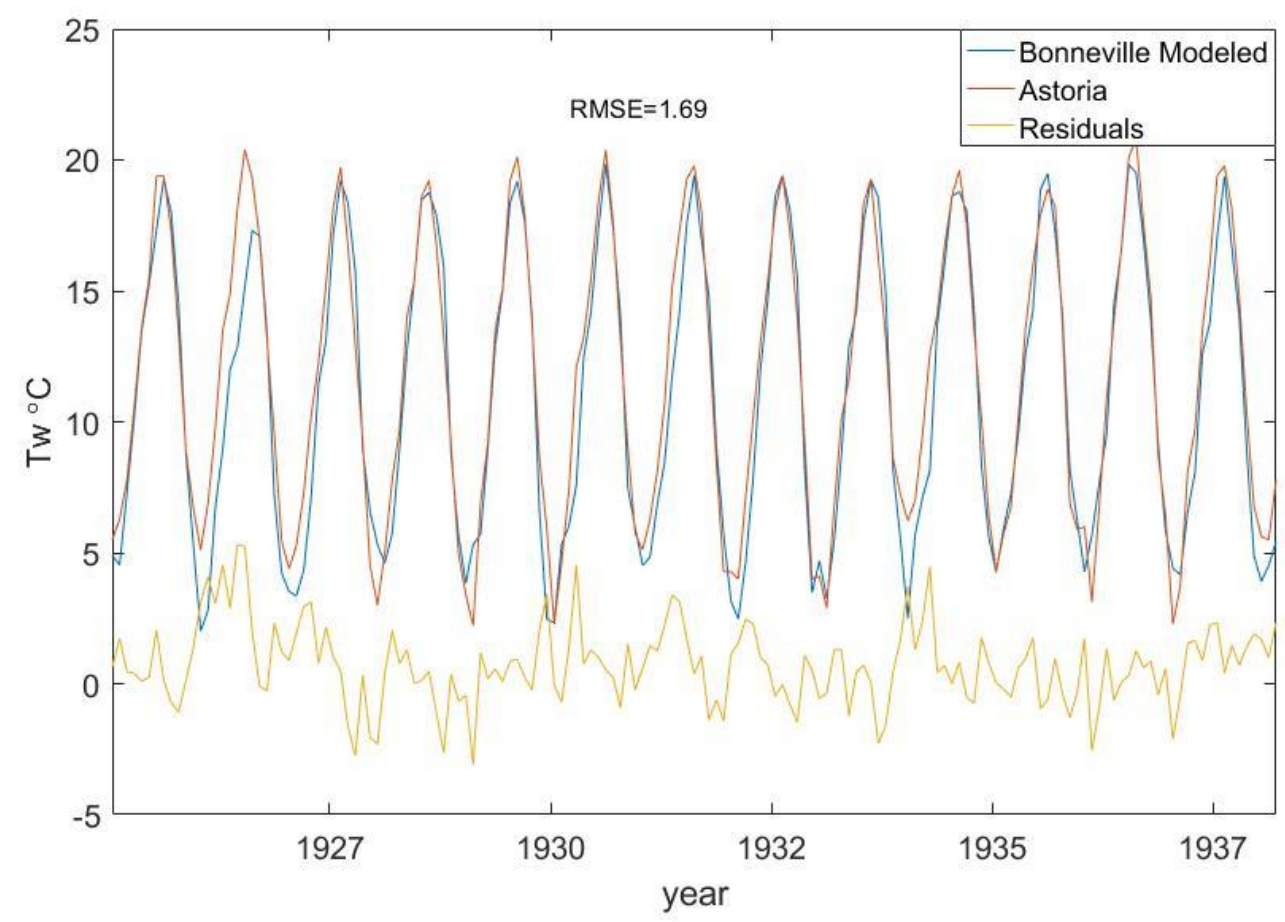

Figure 21. Measured monthly average water temperature $\left(T_{w}\right)$ at Astoria compared to hindcast monthly average $\boldsymbol{T}_{w}$ at Bonneville Dam, 1925-1938. Residuals show modeled Bonneville Dam results subtracted from Astoria measurements.

A closer comparison suggests that much of the higher variance is driven by a few anomalous periods such as the winter and summer of 1926 or the winter of 1934. In several years, the model predicted higher winter and lower summer $T_{w}$ at Bonneville Dam than at Astoria, exactly opposite of the general behavior noted for the 1938-1956 period (Figure 2). It is possible that the error in 
$T_{a}$ measurements is larger in the early $20^{\text {th }}$ century, driving a larger variance. Moreover, the model may not represent identical conditions to the hindcasted period, since no dams existed prior to 1934. The modeled summer $T_{w}$ was especially low in 1926, which could be explained by unusual conditions that year. During that year, peak $Q$ was less than 7,000 $\mathrm{m}^{3} / \mathrm{s}$, which was exceptionally low for the pre-management period. When 1926 was not included in the comparison of the modeled and observed $T_{w}$, the RMSE decreased to $1.48^{\circ} \mathrm{C}$.

Hindcasted $T_{w}$ for 1915-1938 did not show as much variability in summertime maximums as measured values did for 1938-1956 (Figure 22). The years with highest modeled $T_{w}$ were 1926, 1930, 1931 and 1936. The highest $T_{w}$ value for the 1915-1938 period occurred in 1936 and was $20.1^{\circ} \mathrm{C}$, lower than the $1938-1956$ period maximum of $22.3^{\circ} \mathrm{C}$ that occurred in 1941 . There was much more variability in wintertime low $T_{w}$. The lowest modeled $T_{w}$ occurred during the winters of $1919 / 20,1928 / 29,1929 / 30,1935 / 36$, and 1936/37. The accuracy of the model is likely not sufficient to determine whether $T_{w}$ in the 1915-1938 period was statistically different than the 1938-1956 period.

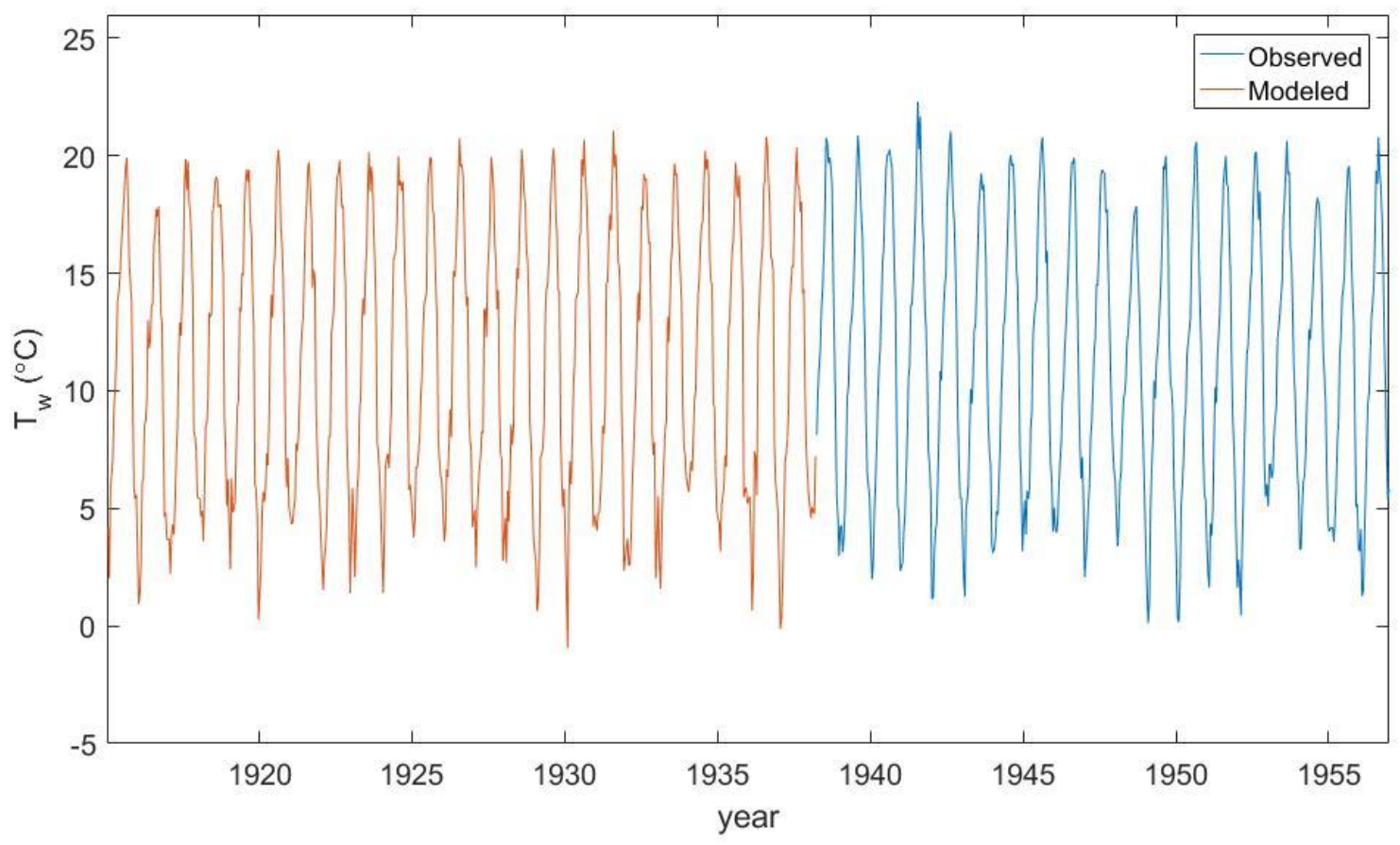

Figure 22. Hindcasted biweekly average water temperature $\left(T_{w}\right)$ at Bonneville Dam, 1915-1938, shown in red and observed biweekly average $T_{w}$ at Bonneville Dam, 1938-1956, shown in blue. 


\subsection{CONCLUSION}

\subsection{Summary}

In order to study changes in water temperature $\left(T_{w}\right)$ over time, linear regression models of $T_{w}$ based on air temperature $\left(T_{a}\right)$ and streamflow $(Q)$ were developed for the Columbia River. Two periods were used for comparison: a historical period (1938-1956) when few main-stem dams existed on the river, and a modern period (1977-2003) when the river was more managed. The historical model performed better than the modern model, with an overall RMSE of $1.22^{\circ} \mathrm{C}$, compared to $1.43^{\circ} \mathrm{C}$. Neither model had a lower RMSE than the climatological average for the period, but both models better represented interannual variability.

Comparison of the models for the historical and modern periods showed that $T_{w}$ was more sensitive to $Q$ and less sensitive to $T_{a}$ in summer during the modern period. The regression coefficient for $Q$ was $-0.187^{\circ} \mathrm{C} / 10^{3} \mathrm{~m}^{3} / \mathrm{s}$ for the historical period and $-0.318^{\circ} \mathrm{C} / 10^{3} \mathrm{~m}^{3} / \mathrm{s}$ for the modern period. The regression coefficient for $T_{a}$ was $0.539^{\circ} \mathrm{C} /{ }^{\circ} \mathrm{C}$ for the historical period and $0.483{ }^{\circ} \mathrm{C} /{ }^{\circ} \mathrm{C}$ for the modern period. $T_{w}$ anomalies from the climatological average were less sensitive to $T_{a}$ anomalies during the modern period. These differences indicate that the $T_{w} / T_{a}$ and $T_{w} / Q$ relationships have changed over time, probably due to a combination of climate change and reservoir management. The increase in summer $T_{w}$ due to system changes (e.g., reservoir management) and decreased $Q$ was determined to be approximately $1.3^{\circ} \mathrm{C}$.

The $T_{w}$ model for the historical period was also used to hindcast $T_{w}$ at Bonneville Dam for 19151938. These results were compared to monthly average $T_{w}$ measurements from Astoria. The relationship between the model results and the measured data had a higher RMSE than the relationship between measured data at Bonneville Dam and Astoria for 1938-1956. This could be because the historical model is not suited for the pre-dam scenario, or because of errors in the $Q$ or $T_{a}$ data used for hindcasting or the $T_{w}$ data from Astoria. Further investigation into these possibilities would be useful.

\subsection{Next Steps}

The models developed in this study could be improved by different methods of data processing. For example, the sub-basin $T_{a}$ data could be weighted based on each sub-basin's flow contribution rather than area. Different time lags could be used for each sub-basin based on distance from 
Bonneville Dam rather than one time lag for the entire basin average $T_{a}$. It is possible that these methods could better represent the physical nature of the system. More terms could also be added to the regression equation representing multiple time lags on $T_{a}$. This would give further insight into the delayed response of $T_{w}$ to $T_{a}$ in the modern, managed system.

Additional data could also be used to improve the models developed here. The PRISM Climate Group (http://prism.oregonstate.edu/), part of The Northwest Alliance for Computational Science and Engineering, maintains climate records dating back to 1895 . This data would expand the $T_{a}$ data sets used in the model development, which could lead to more accurate models. Similarly, $T_{w}$ and $T_{a}$ measurements through 2017 can be used to assess recent trends and variability, such as the hot summers of 2009 and 2015.

By improving the data used in these models, more accurate models could be developed that would better represent each time period. This would allow for more reliable comparisons between the models for different time periods, as well as better hindcasting capabilities. Additionally, Astoria $T_{w}$ data from 1853-1876 compiled by Talke and Jay (2013) could be incorporated as a way to study $T_{w}$ change over a longer period. 


\subsection{REFERENCES}

Benyahya, L., Caissie, D., St-Hilaire, A., Ouarda, T. B., and Bobée, B. (2007). "A review of statistical water temperature models." Canadian Water Resources Journal, 32(3), 179-192.

Bottom, D. L., Simenstad, C. A., Burke, J., Baptista, A. M., Jay, D. A., Jone, K. K., Casillas, E. and Schiewe, M. H. (2011). "Estuarine habitat and juvenile salmon: current and historical linkages in the lower Columbia River and estuary." National Oceanic and Atmospheric Administration, Northwest Fisheries Science Center, Seattle, WA.

Boyd, M. and Sturdevant, D. (1997). “The scientific basis for Oregon's stream temperature standard: common questions and straight answers." Oregon Department of Environmental Quality.

Carter, K. (2006). "The effects of temperature on steelhead trout, coho salmon, and chinook salmon biology and function by life stage.” California Regional Water Quality Control Board.

Crozier, L. G., Scheuerell, M. D., and Zabel, R. W. (2011). "Using time series analysis to characterize evolutionary and plastic responses to environmental change: a case study of a shift toward earlier migration date in sockeye salmon.” Am. Nat., 178(6), 755-773.

Dittman, A. and Quinn, T. (1996). "Homing in Pacific salmon: mechanisms and ecological basis." J. Exp. Biol., 199(1), 83-91.

Erickson, T. R. and Stefan, H. G. (1996). "Correlations of Oklahoma stream temperatures with air temperatures.” United States Environmental Protection Agency, Duluth, MN.

Erickson, T. R. and Stefan, H. G. (2000). "Linear air/water temperature correlations for streams during open water periods." J. Hydrol. Eng., 5(3), 317-321.

$\mathrm{Gu}$, R. (1998). "A simplified river temperature model and its application to streamflow management." J. Hydrol. (New Zealand), 35-54. 
Hamlet, A. F. and Lettenmaier, D. P. (2005). "Production of temporally consistent gridded precipitation and temperature fields for the continental United States." J. Hydrometeorol., 6(3), 330-336.

Johnson, S. L. (2004). "Factors influencing stream temperatures in small streams: substrate effects and a shading experiment." Can. J. Fish. Aquat. Sci., 61(6), 913-923.

Mayer, T. D. (2012). "Controls of summer stream temperature in the Pacific Northwest." $J$. Hydrol., 475, 323-335.

Mohseni, O. and Stefan, H. G. (1999). "Stream temperature/air temperature relationship: a physical interpretation." J. Hydrol., 218(3), 128-141.

Moore, A. M. (1967). "Correlation and analysis of water-temperature data for Oregon streams." United States Government Printing Office.

Moore, A. M. (1968). "Water temperatures in the lower Columbia River." United States Department of the Interior.

Morrill, J. C., Bales, R. C., and Conklin, M. H. (2005). "Estimating stream temperature from air temperature: implications for future water quality." J. Environ. Eng., 131(1), 139-146.

Naik, P. K. and Jay, D. A. (2005). "Estimation of Columbia River virgin flow: 1879 to 1928." Hydrol. Processes, 19(9), 1807-1824.

Naik, P. K. and Jay, D. A. (2011). "Distinguishing human and climate influences on the Columbia River: changes in mean flow and sediment transport." J. Hydrol., 404(3), 259-277.

Neumann, D. W., Rajagopalan, B., and Zagona, E. A. (2003). "Regression model for daily maximum stream temperature." J. Environ. Eng., 129(7), 667-674.

National Marine Fisheries Service (NMFS). (2016). "2015 adult sockeye salmon passage report." National Oceanic and Atmospheric Administration Fisheries.

National Research Council (NRC). (1996). Upstream: Salmon and society in the Pacific Northwest, National Academy Press, Washington, DC. 
Pilgrim, J. M., Fang, X., and Stefan, H. G. (1998). "Stream temperature correlations with air temperatures in Minnesota: implications for climate warming." J. Am. Water Resour. Assoc., 34(5), 1109-1121.

Quinn, T. P. and Adams, D. J. (1996). "Environmental changes affecting the migratory timing of American shad and sockeye salmon.” Ecology, 77(4), 1151-1162.

Quinn, T. P., Hodgson, S., and Peven, C. (1997). "Temperature, flow, and the migration of adult sockeye salmon (Oncorhynchus nerka) in the Columbia River." Can. J. Fish. Aquat. Sci., 54(6), 1349-1360.

Stefan, H. G. and Preud'homme, E. B. (1993). "Stream temperature estimation from air temperature." J. Am. Water Resour. Assoc., 29(1), 27-45.

USCGS (United States Coast and Geodetic Survey). (1954). "Density of sea water at tide stations: Pacific coast, North and South America, and Pacific Ocean islands." United States Government Printing Office, Washington, DC.

USCGS (United States Coast and Geodetic Survey). (1956). "Surface water temperature at tide stations: Pacific coast, North and South America, and Pacific Ocean islands." United States Government Printing Office, Washington, DC.

USCGS (United States Coast and Geodetic Survey). (1962). "Surface water temperature and salinity: Pacific coast, North and South America, and Pacific Ocean islands." United States Government Printing Office, Washington, DC.

Wagner, R. W., Stacey, M., Brown, L. R., and Dettinger, M. (2011). "Statistical models of temperature in the Sacramento-San Joaquin Delta under climate-change scenarios and ecological implications." Estuaries Coasts, 34(3), 544-556.

Webb, B. W. and Nobilis, F. (1997). "Long-term perspective on the nature of the air-water temperature relationship: a case study." Hydrol. Processes, 11(2), 137-147.

Webb, B. W., Clack, P. D., and Walling, D. E. (2003). "Water-air temperature relationships in a Devon river system and the role of flow." Hydrol. Processes, 17(15), 3069-3084. 
Talke, S. A. and Jay, D. A. (2013). "Nineteenth century North American and Pacific tidal data: Lost or just forgotten?” J. Coast. Res., 29(6a), 118-127.

Ul-Saufie, A. Z., Yahaya, A. S., Ramli, N. A., and Hamid, H. A. (2012). "Robust regression models for predicting PM10 concentration in an industrial area.” Int. J. Eng. Tech., 2(3), 364-370.

Yearsley, J., Karna, D., Peene, S., and Watson, B. (2001). “Application of a 1-D heat budget model to the Columbia River system." Rep. EPA 910-R-01, 4. 